\title{
Left or Right: How Does Amino Acid Chirality Affect the Handedness of Nanostructures Self-Assembled from Short Amphiphilic Peptides?
}

DOI:

10.1021/jacs.7b00847

\section{Document Version \\ Accepted author manuscript}

Link to publication record in Manchester Research Explorer

Citation for published version (APA):

Wang, M., Zhou, P., Wang, J., Zhao, Y., Ma, H., Lu, J., \& Xu, H. (2017). Left or Right: How Does Amino Acid Chirality Affect the Handedness of Nanostructures Self-Assembled from Short Amphiphilic Peptides? Journal of the American Chemical Society. https://doi.org/10.1021/jacs.7b00847

\section{Published in:}

Journal of the American Chemical Society

\section{Citing this paper}

Please note that where the full-text provided on Manchester Research Explorer is the Author Accepted Manuscript or Proof version this may differ from the final Published version. If citing, it is advised that you check and use the publisher's definitive version.

\section{General rights}

Copyright and moral rights for the publications made accessible in the Research Explorer are retained by the authors and/or other copyright owners and it is a condition of accessing publications that users recognise and abide by the legal requirements associated with these rights.

\section{Takedown policy}

If you believe that this document breaches copyright please refer to the University of Manchester's Takedown Procedures [http://man.ac.uk/04Y6Bo] or contact uml.scholarlycommunications@manchester.ac.uk providing relevant details, so we can investigate your claim.

\section{OPEN ACCESS}




$$
\text { ja-2017-00847u.R1 }
$$

Accepted by JACS on 27 Feb 2017

\title{
Left or Right: How Does Amino Acid Chirality Affect the Handedness of Nanostructures Self-Assembled from Short Amphiphilic Peptides?
}

\author{
Meng Wang, ${ }^{\dagger}$ Peng Zhou, ${ }^{\dagger}$ Jiqian Wang, ${ }^{\dagger} * *$ Yurong Zhao, ${ }^{\dagger}$ Hongchao Ma ${ }^{\dagger}$ Jian R. Lu, ${ }^{\ddagger} * *$ \\ and Hai $\mathrm{Xu}^{\dagger}, *$ \\ ${ }^{\dagger}$ State Key Laboratory of Heavy Oil Processing and Centre for Bioengineering and \\ Biotechnology, China University of Petroleum (East China), 66 Changjiang West Road, \\ Qingdao 266555, China \\ *Biological Physics Laboratory, School of Physics and Astronomy, University of \\ Manchester, Schuster Building, Manchester M13 9PL, UK
}

\section{Email Address:}

wangmeng19880210@163.com (Miss Meng Wang)

zhpayne@163.com (Dr. Peng Zhou)

jqwang@upc.edu.cn (Dr. Jiqian Wang)

yurongzhao@upc.edu.cn (Dr. Yurong Zhao)

mahc@upc.edu.cn (Dr. Hongchao Ma)

j.lu@manchester.ac.uk (Prof. Jian R. Lu) 
xuh@upc.edu.cn (Prof. Hai Xu) 


\section{TOC:}
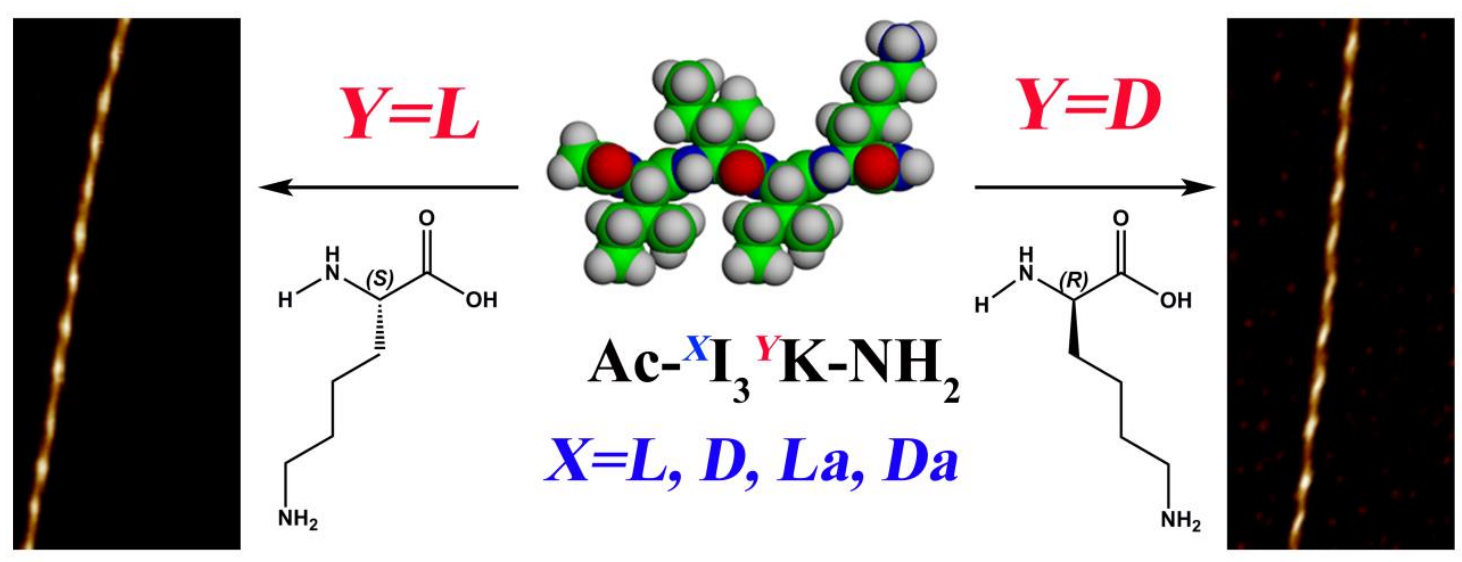


\section{ABSTRACT}

Peptide and protein fibrils have attracted an enormous amount of interests due to their relevance to many neurodegenerative diseases and their potential applications in nanotechnology. Although twisted fibrils are regarded as the key intermediate structures of thick fibrils or bundles of fibrils, the factors determining their twisting tendency and their handedness development from the molecular to the supramolecular level are still poorly understood. In this study, we have designed three pairs of enantiomeric short amphiphilic peptides: ${ }^{L} \mathrm{I}_{3}{ }^{L} \mathrm{~K}$ and ${ }^{D} \mathrm{I}_{3}{ }^{D} \mathrm{~K},{ }^{L} \mathrm{I}_{3}{ }^{D} \mathrm{~K}$ and ${ }^{D} \mathrm{I}_{3}{ }^{L} \mathrm{~K}$, and ${ }^{L a} \mathrm{I}_{3}{ }^{L} \mathrm{~K}$ and ${ }^{D a} \mathrm{I}_{3}{ }^{D} \mathrm{~K}$, and investigated the chirality of their self-assembled nanofibrils through the combined use of atomic force microscopy (AFM), circular dichroism (CD) spectroscopy, scanning electron microscopy (SEM), and molecular dynamic (MD) simulations. The results indicated that the twisted handedness of the supramolecular nanofibrils was dictated by the chirality of the hydrophilic Lys head at the C-terminal, whilst their characteristic CD signals were determined by the chirality of hydrophobic Ile residues. MD simulations delineated the handedness development from molecular chirality to supramolecular handedness by showing that the $\beta$-sheets formed by ${ }^{L} \mathrm{I}_{3}{ }^{L} \mathrm{~K},{ }^{L a} \mathrm{I}_{3}{ }^{L} \mathrm{~K}$, and ${ }^{D} \mathrm{I}_{3}{ }^{L} \mathrm{~K}$ exhibited a propensity to twist in a left-handed direction while the ones of ${ }^{D} \mathrm{I}_{3}{ }^{D} \mathrm{~K},{ }^{D a} \mathrm{I}_{3}{ }^{D} \mathrm{~K}$, and ${ }^{L} \mathrm{I}_{3}{ }^{D} \mathrm{~K}$ in a right-handed twisting orientation. 


\section{INTRODUCTION}

Coiling or twisting is ubiquitous in nature, from the microscopic to the macroscopic scale.

Both left-handed and right-handed coils or twists have been observed, such as peptide secondary structures (right-handed $\alpha$-helices and $\beta$-stands), DNA double helices (right-handed A- and B-DNA and left-handed Z-DNA helices), seashells, plants, and galaxies. ${ }^{1-2}$ Although the handedness of the supramolecular and macroscopic twists is generally species-specific and perceived to be related to shape and interaction asymmetry, the underlying mechanisms and the handedness development from one level to another are not yet well understood. ${ }^{1-5}$

For peptides and proteins, the chirality of the constituent amino acids is widely regarded as a key factor that controls the handedness of their folding and supramolecular organization. As the naturally occurring amino acids are nearly all $L$-amino acids except for glycine, the peptides composed of $L$-amino acid residues usually form right-handed $\alpha$-helices and right-handed twisted $\beta$-strands upon folding, while the left-handed ones are energetically unfavorable. ${ }^{6-8}$ When the right-handed twisted $\beta$-strands pack into $\beta$-sheets along the hydrogen bonding direction, a left-handed twist in the $\beta$-sheet can be generated, and the subsequent lateral stacking of the left-handed $\beta$-sheets is expected to produce fibrils with a left-handed twist. ${ }^{9-11}$ As a result, the observed amyloid fibrils with a characteristic cross- $\beta$ structure are often left-handed twisted. ${ }^{10,12-17}$ In contrast, the fibrils 
from designed peptides comprised of $D$-amino acids usually showed a right-handed twist. ${ }^{11,12,18}$ In spite of the predominance of left-handedness, some fibrillar aggregates formed by natural peptides and proteins have been observed to show a right-handed twist. ${ }^{13,19-23}$ The right-handed fibrils were mostly formed in vitro by small fragments of amyloid polypeptides and proteins such as the $\mathrm{SAA}_{1-12}$ peptide (RSFFSFLGEAFD) from serum amyloid A protein (SAA), ${ }^{13,19}$ and the ILQINS sequence from hen egg white lysozyme. ${ }^{22}$ Furthermore, their formation was often realized under aqueous acidic conditions ( $\mathrm{pH} 2.0$ or lower), ${ }^{13,19,20,22,23}$ and even at a relatively higher temperature, ${ }^{20,23}$ probably due to their high hydrophobicity or low solubility in aqueous solution. These studies indicate that it is currently difficult to unequivocally predict the handedness of supramolecular nanostructures based on a known peptide sequence. In fact, the rationale underpinning the handedness development and inversion might be complex. Either the adoption of $\beta$-helices which form both left- and right-handed helices irrespective of the chirality of constituent amino acids or the terminus interactions along the peptide backbone direction, has been postulated to be the likely cause. ${ }^{13,19,22}$ In a recent study, Usov et al have identified the coexistence of left- and right-handed twisted fibrils self-assembled from bovine serum ovalbumin (BSA) at $\mathrm{pH} 2.0$ and $90{ }^{\circ} \mathrm{C}$, and more importantly, they clearly observed that the right-handed rigid fibrils were formed by winding of two left-handed flexible fibrils, through high resolution AFM imaging. ${ }^{20,21}$ 
Thus, the increasing structural complexity during fibril thickening might be one of the causes of the handedness inversion from left-handed to right-handed.

In addition to homochiral peptides, heterochiral peptides composed of both $L$ - and $D$-amino acids have recently received a lot of interests thanks to their unusual self-assembling behaviors. ${ }^{24-30}$ For example, Marchesan et al have demonstrated that for the tripeptides FFV, only when the chirality of the N-terminal amino acid was different from that of the rest in their sequences, the resulting tripeptides $\left({ }^{D} \mathrm{~F}^{L} \mathrm{~F}^{L} \mathrm{~V}\right.$ and $\left.{ }^{{ }^{L}} \mathrm{~F}^{D} \mathrm{~F}^{D} \mathrm{~V}\right)$ were able to adopt well-defined $\beta$-sheet conformations and self-assembled into fibrils under physiological conditions, while no ordered structures and gelation were observed for homochiral tripeptides $\left({ }^{L} \mathrm{~F}^{L} \mathrm{~F}^{L} \mathrm{~V}\right.$ and $\left.{ }^{D} \mathrm{~F}^{D} \mathrm{~F}^{D} \mathrm{~V}\right)$ and other heterochiral ones $\left({ }^{D} \mathrm{~F}^{D} \mathrm{~F}^{L} \mathrm{~V}\right.$, ${ }^{D} \mathrm{~F}^{L} \mathrm{~F}^{D} \mathrm{~V},{ }^{L} \mathrm{~F}^{D} \mathrm{~F}^{L} \mathrm{~V}$, and $\left.{ }^{L} \mathrm{~F}^{L} \mathrm{~F}^{D} \mathrm{~V}\right) .{ }^{25}$ Very recently, they have found that ${ }^{L} \mathrm{~F}^{D} \mathrm{~L}^{L} \mathrm{~F}$ could form self-supportive hydrogels at the physiological $\mathrm{pH}$ by self-assembling into $D$-amphiphilic superstructures and then into thick fibrils, implying the potential and versatility of amino acid chirality in tuning peptide self-assembly and gelation. ${ }^{27}$ On the contrary, Luo et al. have found that both ${ }^{L} \mathrm{E}^{L} \mathrm{~A}{ }^{L} \mathrm{~K} 16$ and ${ }^{D} \mathrm{E}^{D} \mathrm{~A}^{D} \mathrm{~K} 16$ self-assembled into well-ordered nanofibers whereas heterochiral peptides ${ }^{L} \mathrm{E}^{D} \mathrm{~A}^{L} \mathrm{~K} 16$ and ${ }^{D} \mathrm{E}^{L} \mathrm{~A}^{D} \mathrm{~K} 16$ showed poor self-assembling properties. ${ }^{28}$ Interestingly, Fu et al have synthesized two pairs of dipeptide enantiomers linked by attachment to a hydrophobic $\mathrm{C} 18$ chain at their N-termini $\left(\mathrm{C}_{18} \mathrm{H}_{35} \mathrm{O}-{ }^{L} \mathrm{~A}^{L} \mathrm{~A}\right.$ and $\mathrm{C}_{18} \mathrm{H}_{35} \mathrm{O}-{ }^{D} \mathrm{~A}^{D} \mathrm{~A} ; \mathrm{C}_{18} \mathrm{H}_{35} \mathrm{O}-{ }^{D} \mathrm{~A}^{L} \mathrm{~A}$ and $\left.\mathrm{C}_{18} \mathrm{H}_{35} \mathrm{O}-{ }^{L} \mathrm{~A}^{D} \mathrm{~A}\right)$ and 
found that the chirality of their self-assembled aggregates was controlled by the chirality of the alanine at the C-terminal, i.e., $\mathrm{C}_{18} \mathrm{H}_{35} \mathrm{O}_{-}{ }^{L} \mathrm{~A}^{L} \mathrm{~A}$ and $\mathrm{C}_{18} \mathrm{H}_{35} \mathrm{O}-{ }^{D} \mathrm{~A}^{L} \mathrm{~A}$ self-assembled into left-handed twisted ribbons while $\mathrm{C}_{18} \mathrm{H}_{35} \mathrm{O}_{-}{ }^{D} \mathrm{~A}^{D} \mathrm{~A}$ and $\mathrm{C}_{18} \mathrm{H}_{35} \mathrm{O}^{-}{ }^{L} \mathrm{~A}^{D} \mathrm{~A}$ formed right-handed ones. ${ }^{29}$ Thus, such a study points to the importance of terminal residues in tuning the handedness of supramolecular structures. In fact, because the dipeptide (AA) acted as the hydrophilic head group and upon self-assembly, the C-terminal alanine residues were located on the surface of the self-assembled aggregates, it can be anticipated that terminal interactions (e.g. hydrogen bonding, ionic, and steric interactions) play an important role in tuning the supramolecular morphology, as also discussed by Lara et al. ${ }^{22}$

Although some hypotheses have been proposed in terms of the handedness changes of peptide and protein assemblies with variations in incubation conditions and sequences, ${ }^{13,19,20-22,29}$ factors defining supramolecular chirality and handedness development from the molecular level to the supramolecular assembly remain largely elusive. ${ }^{21,22}$ To mechanistically understand these critical issues in peptide self-assembly, we here design three pairs of short peptide enantiomers, i.e., ${ }^{L} \mathrm{I}_{3}{ }^{L} \mathrm{~K}$ and ${ }^{D} \mathrm{I}_{3}{ }^{D} \mathrm{~K},{ }^{L} \mathrm{I}_{3}{ }^{D} \mathrm{~K}$ and ${ }^{D} \mathrm{I}_{3}{ }^{L} \mathrm{~K}$, and ${ }^{L a} \mathrm{I}_{3}{ }^{L} \mathrm{~K}$ and ${ }^{D a} \mathrm{I}_{3}{ }^{D} \mathrm{~K}$ (Figure $1 \mathrm{~b}$ ), and investigate their self-assembly at $\mathrm{pH}$ 7.0, focusing on the handedness of the molecular conformations and the self-assembled nanostructures. Note that isoleucine is a particular amino acid, which not only exhibits 
high hydrophobicity and strong propensity for $\beta$-sheet structuring in protein folding but also has two chiral centers, i.e., the $\alpha$-carbon $\left(\mathrm{C}_{\alpha}\right)$ and the side-chain $\beta$-carbon $\left(\mathrm{C}_{\beta}\right)$ atoms. Correspondingly, there are two pairs of isoleucine enantiomers, i.e., $L$-isoleucine $(2 S, 3 S)$ $(L$-Ile) and $D$-isoleucine $(2 R, 3 R)(D$-Ile $)$, and $L$-allo-isoleucine $(2 S, 3 R)(L$-alle $)$ and $D$-allo-isoleucine $(2 R, 3 S)(D$-aIle), as shown in Figure 1a. As a result, the designed molecules include both homochiral and heterochiral peptides. Furthermore, the $\alpha$ carbon atoms along the peptide backbone of the heterochiral peptides are either homogeneous or heterogeneous in chirality. These molecular features allow us to systematically follow the effect of the molecular chirality of the constituent amino acids and the sequences.

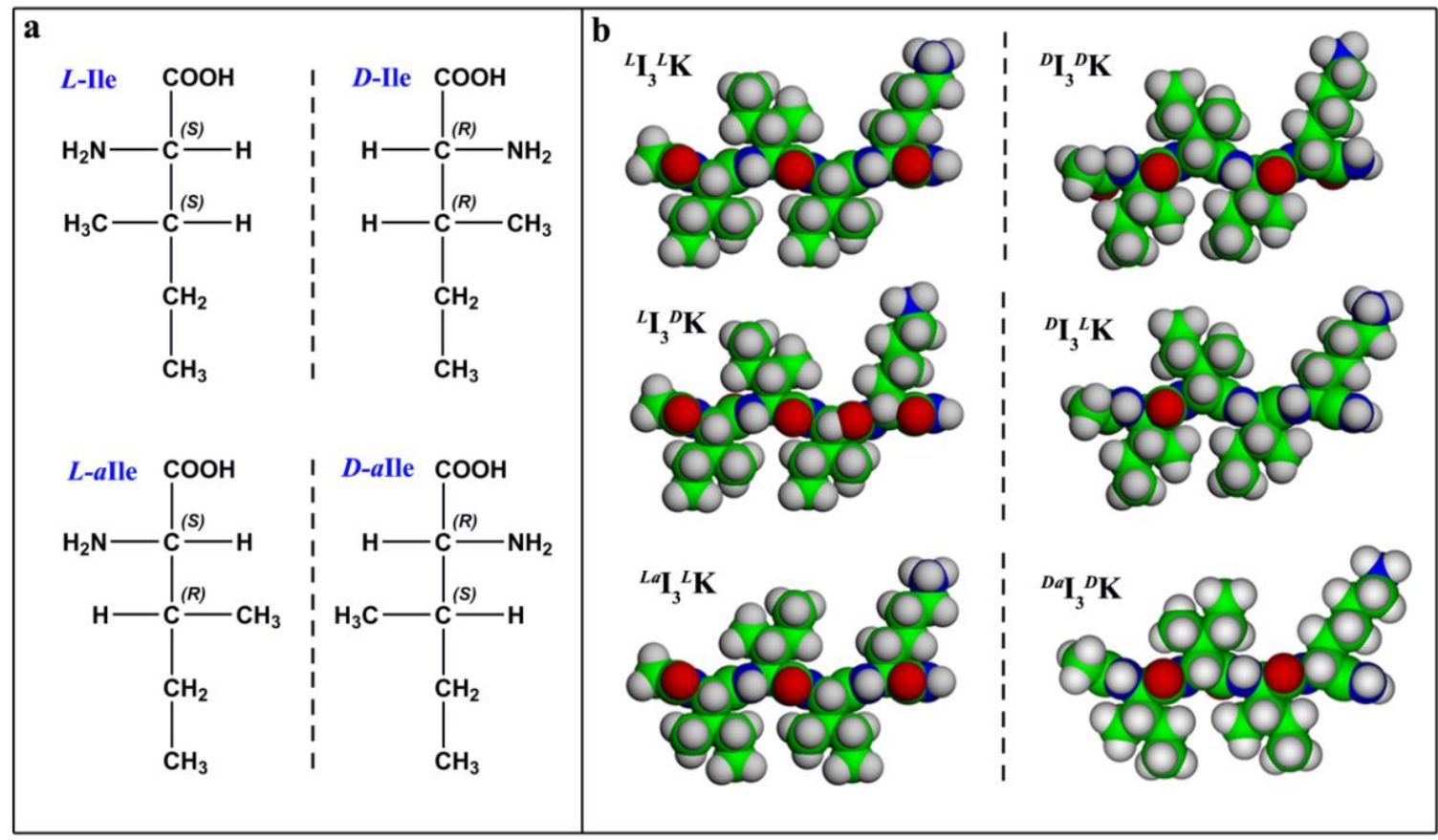

Figure 1. (a) Fischer projections of four isoleucine stereoisomers. (b) Molecular structures of the three pairs of $\mathrm{I}_{3} \mathrm{~K}$ enantiomers. 


\section{RESULTS AND DISCUSSION}

In order to eliminate the electrostatic effect of the terminal carboxylate and amine groups, both termini were capped in the designed peptides (C-terminal amidation and $\mathrm{N}$-terminal acetylation) unless otherwise specified. These peptides were synthesized in our laboratory based on the standard Fmoc solid-phase synthesis strategy. After purification, the collected products were analyzed using reversed-phase high-performance liquid chromatography (RP-HPLC) and matrix-assisted laser desorption/ionization time-of-flight mass spectroscopy (MALDI-TOF MS). The results not only indicated the correct sequences and high purities (more than 98\%), but also revealed the same hydrophobicity of the six stereoisomers (Figure S1 and S2).

The designed short peptides are structurally akin to conventional surfactants, three consecutive isoleucine residues acting as their hydrophobic tail while a positively charged lysine functioning as the hydrophilic head. Our previous study has shown that ${ }^{L} \mathrm{I}_{3}{ }^{L} \mathrm{~K}$ not only had high solubility in water, but also self-assembled into thin fibrils at neutral $\mathrm{pH}$, driven by molecular amphiphilicity in combination with the intermolecular $\beta$-sheet hydrogen bonding. ${ }^{31,32}$ In this study, their self-assembly in neutral water ( $\mathrm{pH} 7.0$ ) was first assessed using the thioflavin-T (ThT) binding assay. As shown in Figure S3, the peptides all induced an enhanced fluorescence emission of ThT at around $480 \mathrm{~nm}$, indicative of the formation of amyloid-like fibrils with $\beta$-sheet structures. ${ }^{33,34}$ Furthermore, the degree 
of the fluorescence enhancement was different: ${ }^{L a} I_{3}{ }^{L} \mathrm{~K}$ caused the strongest fluorescence enhancement while the pair of ${ }^{L}{ }_{3}{ }^{D} \mathrm{~K}$ and ${ }^{D} \mathrm{I}_{3}{ }^{L} \mathrm{~K}$ enantiomers induced the weakest enhancement, implying an effect of amino acid chirality. However, the effect should not be as significant as that observed by Marchesan et al and Luo et al, in which the chirality at one amino acid position drastically altered their self-assembling properties from all to none or vice versa. ${ }^{24-28}$ Consequently, negative-staining transmission electron microscopy (TEM) measurements indicated that all the peptides could form long and twisted nanofibrils with widths ranging from 10 to $20 \mathrm{~nm}$ (Figure S4). The unusual self-assembling ability of these short peptides most likely arises from the high hydrophobicity and strong propensity for $\beta$-sheet structuring of isoleucine, as well as their amphiphilic feature. However, it is quite difficult to determine the handedness of the thin peptide fibrils from negative-staining TEM imaging, because only projection images were obtained via this technique. ${ }^{13}$

Atomic force microscopy (AFM) is able to provide high-resolution 3D images and is thus appropriate to deduce the handedness of thin nanofibrils. ${ }^{13,20,21}$ As expected, the fibrils formed by ${ }^{{ }_{\mathrm{I}}}{ }_{3}{ }^{L} \mathrm{~K}$ showed a well-defined left-handed twist from AFM height imaging (Figures 2a and 2b). By using the AFM manufacturer's software (NanoScope Analysis), the height along the fibril axis could be directly tracked, revealing a zigzag pattern with a uniform pitch of $118 \pm 3 \mathrm{~nm}$ and the height fluctuation between 7 to $12 \mathrm{~nm}$ 
(Figures 2a and 2c). For fiber-like objects, Usov and Mezzenga have developed an open-source code called FiberApp to accurately track their contour and analyze their structural and topological features with statistical significance. ${ }^{35}$ FiberApp has shown potential in assessing high-resolution images of AFM, TEM, fluorescence, confocal, etc. ${ }^{20,35,36}$ By using the height autocorrelation function (ACF) of FiberApp based on more twisted fibrils after their tracking, the pitch (periodicity) was determined to be $122 \mathrm{~nm}$ (Figure 2d), consistent with that obtained from NanoScope Analysis. Usov et al have observed that two flexible left-handed twisted ribbons could combine together to form a right-handed one. ${ }^{20}$ In this case, we also observed the interwinding of two or three left-handed twisted fibrils, but the thick fibrils formed still displayed a left-handed twist, as indicated by a blue arrow in Figure $2 \mathrm{~b}$. In contrast, the twisted fibrils formed by its enantiomer ${ }^{D} \mathrm{I}_{3}{ }^{D} \mathrm{~K}$ were exclusively right-handed (Figures $2 \mathrm{e}$ and $2 \mathrm{f}$ ). The section profile along the fibril axis indicated a uniform pitch of $110 \pm 3 \mathrm{~nm}$ and a height fluctuation from 10 to $13 \mathrm{~nm}$ (Figures $2 \mathrm{e}$ and $2 \mathrm{~g}$ ), the former being in line with the periodicity of $114 \mathrm{~nm}$ obtained from the height ACF of FiberApp also on twisted fibrils (Figure 2h). Again, the thick fibrils combined by right-handed thin fibrils remained right-handed, as indicated by blue arrows in Figure $2 \mathrm{e}$ and no handedness inversion was observed with the morphological evolution. 


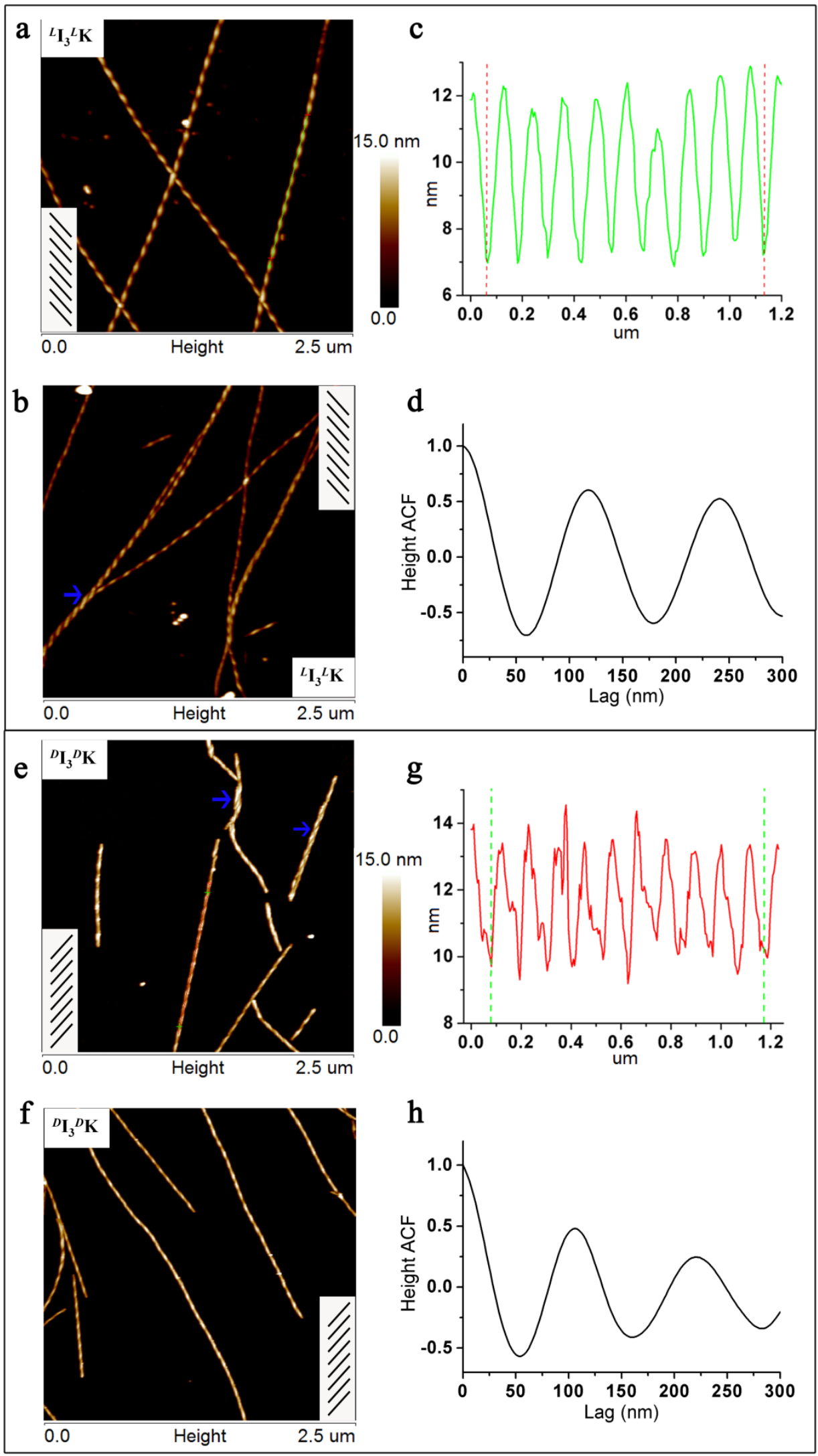


Figure 2. AFM images of (a,b) ${ }^{{ }^{L} \mathrm{I}_{3}}{ }^{L} \mathrm{~K}$ and $(\mathrm{e}, \mathrm{f}){ }^{D} \mathrm{I}_{3}{ }^{D} \mathrm{~K}$ fibrils formed at a concentration of $8 \mathrm{mM}$ in neutral water. (c,g) The section profiles obtained from NanoScope Analysis (Bruker) giving the height fluctuation along the fibril axis and the helical pitch. (d,h) FiberApp height autocorrelation function (ACF) defining the pitch (periodicity) of fibrils with statistical significance. Blue arrows of (b) and (e) indicated the interwinding of two or three thin fibrils into thick ones.

$D$-Ile and $L$-Ile are enantiomers, being opposite in the absolute configuration of both $\mathrm{C}_{\alpha}$ and $\mathrm{C}_{\beta}$ chiral centers. As for the pair of ${ }^{D} \mathrm{I}_{3}{ }^{L} \mathrm{~K}$ and ${ }^{L} \mathrm{I}_{3}{ }^{D} \mathrm{~K}$ enantiomers, the $\alpha$ carbon atoms along the peptide backbone are heterogeneous in chirality, which may disfavor the hydrogen bonding between backbones. As a consequence, the weakest fluorescence enhancement of ThT was induced by the two heterochiral peptides (Figure S3). After ThT binding, Marchesan et al. have previously observed weak fluorescence with the heterochiral tripeptides (e.g. ${ }^{L} \mathrm{~V}^{D} \mathrm{~F}^{L} \mathrm{~F}$ and ${ }^{D} \mathrm{~V}^{L} \mathrm{~F}^{D} \mathrm{~F}$ ) that had less $\beta$-sheets and lower supramolecular order incorporated into fibrils and weak hydrogels. ${ }^{26}$ Similarly, TEM, AFM, and scanning electron microscopy (SEM) measurements revealed the formation of thin and twisted nanofibrils for ${ }^{D} \mathrm{I}_{3}{ }^{L} \mathrm{~K}$ and ${ }^{L} \mathrm{I}_{3}{ }^{D} \mathrm{~K}$ (Figure 3, Figure S4, and Figure S5). Interestingly, when the three hydrophobic $L$-Ile residues were replaced by three $D$-Ile ones, the ${ }^{D} \mathrm{I}_{3}{ }^{L} \mathrm{~K}$ nanofibrils were still left-handed twisted (Figure 3a), which was the same as the ${ }^{L}{ }_{3}{ }^{L} \mathrm{~K}$ ones.

Correspondingly, when the hydrophilic $L$-Lys residue was replaced by its enantiomer 
(D-Lys), the handedness inversion occurred and the ${ }^{{ }_{\mathrm{I}}}{ }_{3}{ }^{D} \mathrm{~K}$ nanofibrils were right-handed twisted (Figure 3d), the same as the ${ }^{D} \mathrm{I}_{3}{ }^{D} \mathrm{~K}$ ones. These results clearly indicated the crucial role of the hydrophilic amino acid chirality at the C-terminal in determining the handedness of the self-assembled nanostructures formed by the short amphiphilic peptides, consistent with the findings of $\mathrm{Fu}$ et al on the lipopeptides $\mathrm{C}_{18} \mathrm{H}_{35} \mathrm{O}-\mathrm{AA} \cdot{ }^{29} \mathrm{In}$ contrast, the chirality of the hydrophobic tail residues seemed to have little impact. In fact, the C-terminal amino acids act as the hydrophilic head group for these amphiphilic peptides and upon self-assembly in aqueous solution, they are located on the surface of assemblies. ${ }^{31}$ As a result, the residues can be expected to play an important role in defining the morphology of the assemblies such as the curvature and the handedness via non-covalent interactions (hydrogen bonding and electrostatic interactions) in combination with steric constraints. Additionally, section profiling along the fibril axis indicated a uniform pitch of $90 \pm 3 \mathrm{~nm}$ and heights fluctuating mostly between 5 and 10 $\mathrm{nm}$ for the ${ }^{D} \mathrm{I}_{3}{ }^{L} \mathrm{~K}$ nanofibrils (Figures $3 \mathrm{a}$ and 3b). By using FiberApp software, height ACF analysis resulted in a statistical pitch of $96 \mathrm{~nm}$ (Figure 3c). In the case of ${ }^{L} \mathrm{I}_{3}{ }^{D} \mathrm{~K}$, however, there were two types of left-handed twisted nanofibrils (Figures $3 \mathrm{~d}$ and 3e). Section analysis along the fibril axis revealed that both had uniform pitches and regular height fluctuations, but one had a pitch of $64 \pm 3 \mathrm{~nm}$, with height varying from 6 to $11 \mathrm{~nm}$ (red curve of Figure 3e) and another had a pitch of $90 \pm 3 \mathrm{~nm}$ and a height fluctuation from 
6 to $15 \mathrm{~nm}$ (green curve of Figure 3e). Consistently, height ACF analysis revealed two statistical pitches of 64 and $92 \mathrm{~nm}$, respectively (Figure 3f). It was evident that the pitch of the twisted fibrils increased with their height, an observation also reported by other researchers. ${ }^{20,37,38}$ However, this was not the case when comparing different fibrils formed by different peptides. For example, the ${ }^{{ }} \mathrm{I}_{3}{ }^{L} \mathrm{~K}$ fibrils displayed the largest pitch in spite of their medium heights or widths.

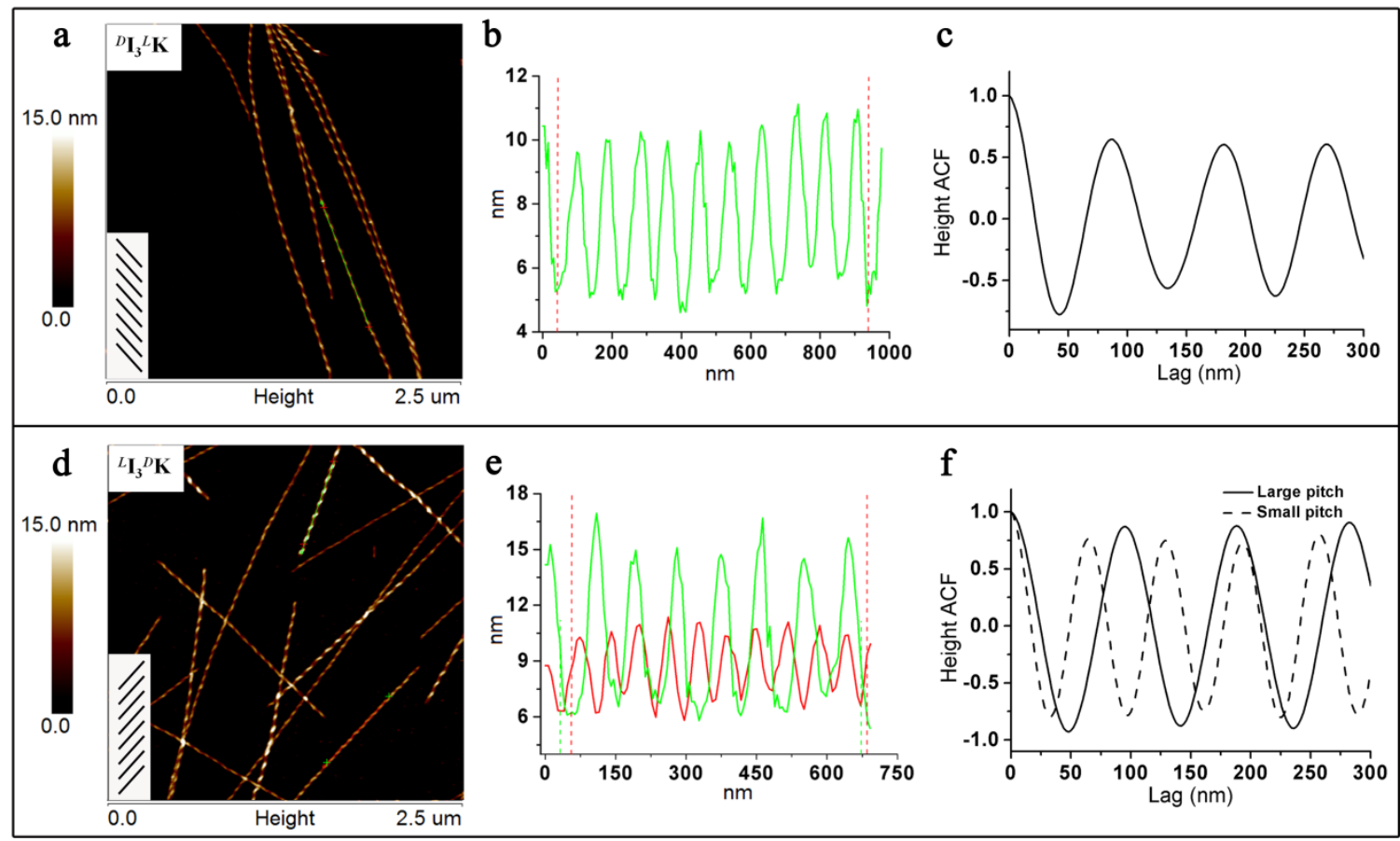

Figure 3. AFM images of (a) ${ }^{D} \mathrm{I}_{3}{ }^{L} \mathrm{~K}$ and (d) ${ }^{{ }} \mathrm{I}_{3}{ }^{D} \mathrm{~K}$ fibrils formed at a concentration of $8 \mathrm{mM}$ in neutral water. (b,e) The section profiles obtained from NanoScope Analysis (Bruker) giving the height variation along the fibril axis and the helical pitch. (c,f) FiberApp height autocorrelation function (ACF) defining the pitch (periodicity) of twisted fibrils with statistical significance.

$L$-allo-Ile and $L$-Ile are epimers of each other, differing in the absolute configuration 
only at one chiral center, i.e., the $\mathrm{C}_{\beta}$ atom ( $3 R$ versus $3 S$ ) while their $\mathrm{C}_{\alpha}$ atoms have the same configuration $(2 S)$. Similarly, $D$-allo-Ile and $D$-Ile have the same $2 R$ configuration around the $\mathrm{C}_{\alpha}$ atom, differing from each other in the configuration around the $\mathrm{C}_{\beta}$ atom ( $3 S$ versus $3 R$ ). The $\alpha$ carbon atoms in the peptide backbone have the same chirality for either ${ }^{L a} \mathrm{I}_{3}{ }^{L} \mathrm{~K}$ and ${ }^{L} \mathrm{I}_{3}{ }^{L} \mathrm{~K}$ or ${ }^{D a} \mathrm{I}_{3}{ }^{D} \mathrm{~K}$ and ${ }^{D} \mathrm{I}_{3}{ }^{D} \mathrm{~K}$. As a result, strong fluorescence enhancement of ThT was also induced by the two heterochiral peptides, the same as the pair of ${ }^{L}{ }_{3}{ }^{L} \mathrm{~K}$ and ${ }^{D} \mathrm{I}_{3}{ }^{D} \mathrm{~K}$; in particular, ${ }^{L a} \mathrm{I}_{3}{ }^{L} \mathrm{~K}$ caused the strongest fluorescence enhancement (Figure S3). These results suggested strong $\beta$-sheet hydrogen bonding between peptide backbones also for the two heterochiral peptides. In the case of ${ }^{L a} \mathrm{I}_{3}{ }^{L} \mathrm{~K}$, many nanofibrils were thus formed, and they showed polymorphism in helical pitch (Figure 4a). The thick fibrils showed a clear left-handedness (inset of Figure 4a), and section analysis along the fibril axis indicated the pitch of $80-90 \mathrm{~nm}$ and height mostly fluctuating between 6 to 10 nm (red curve of Figure 4b). Their average pitch with statistical significance was determined to $82 \mathrm{~nm}$ by using FiberApp software (Figure 4c). In addition, thin fibrils with height of less than $6 \mathrm{~nm}$ were often observed (Figure 4a). In fact, section analysis revealed that the thin fibrils were also twisted, with pitch values of $20-30 \mathrm{~nm}$ (green curve of Figure $4 \mathrm{~b}$ ). For ${ }^{D a} \mathrm{I}_{3}{ }^{D} \mathrm{~K}$, right-handed twisted nanofibrils were formed (Figure 4d). Section profiling indicated two main types of twisted fibrils (Figure 4e), one having a relatively uniform pitch of $117 \pm 3 \mathrm{~nm}$ and height fluctuating between 8 and $12 \mathrm{~nm}$ 
(green curve) and another having a relatively uniform pitch of $92 \pm 3 \mathrm{~nm}$ and height fluctuating between 7 and $10 \mathrm{~nm}$ (red curve). By using FiberApp, their average pitch with statistical significance was determined to be 124 and $96 \mathrm{~nm}$, respectively (Figure 4f). In spite of various polymorphic states associated with the fibrils formed by ${ }^{L a} \mathrm{I}_{3}{ }^{L} \mathrm{~K}$ and ${ }^{D a} \mathrm{I}_{3}{ }^{D} \mathrm{~K}$, their morphological handedness was still dictated by the chirality of the C-terminal Lys residue, i.e., the ${ }^{L a} \mathrm{I}_{3}{ }^{L} \mathrm{~K}$ fibrils were left-handed twisted, whilst the ${ }^{D a} \mathrm{I}_{3}{ }^{D} \mathrm{~K}$ were right-handed twisted. For the thin ${ }^{L a} \mathrm{I}_{3}{ }^{L} \mathrm{~K}$ fibrils with much shorter pitches, it was hard to determine their handedness from AFM and SEM measurements.

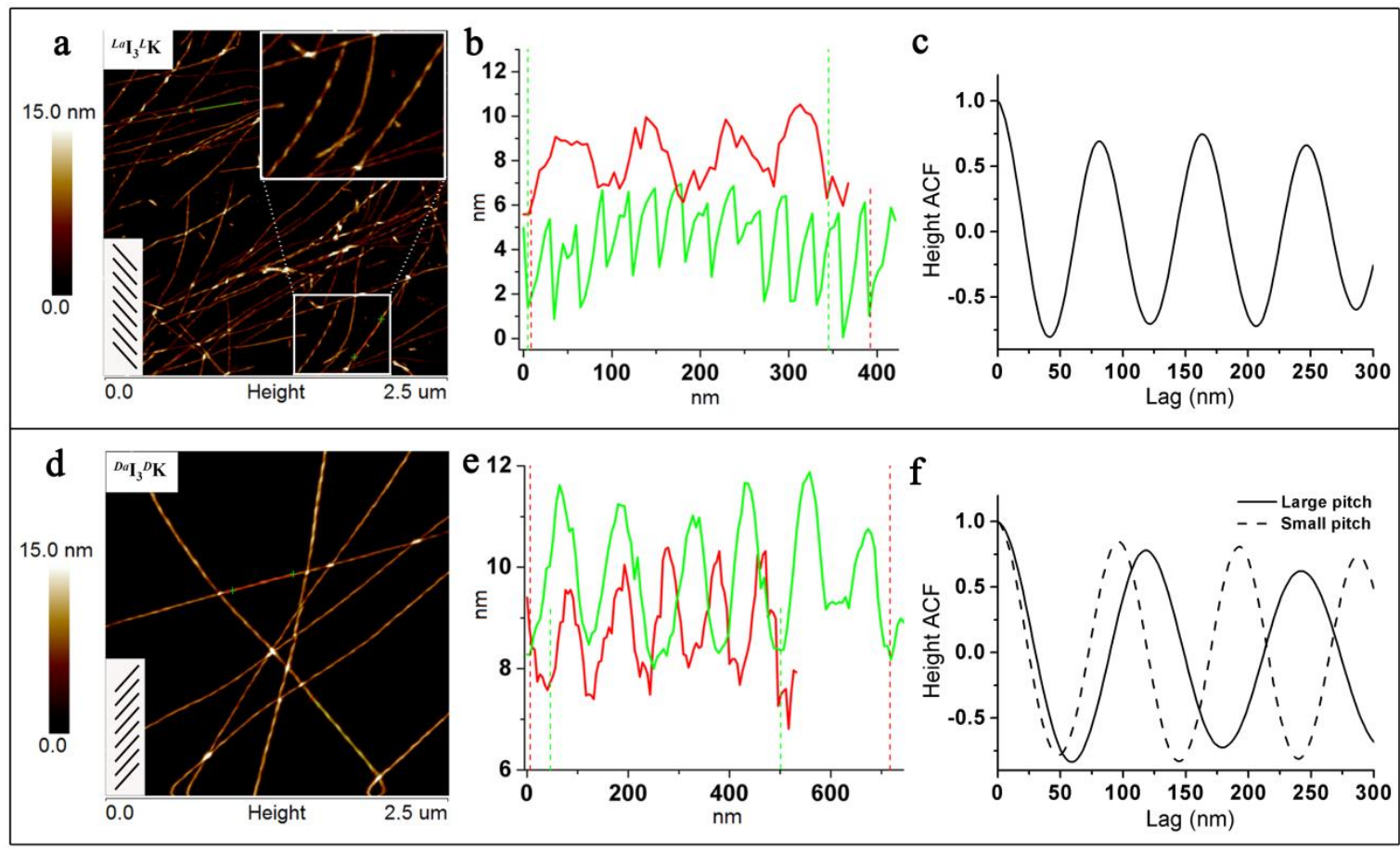

Figure 4. AFM images of (a) ${ }^{L a} \mathrm{I}_{3}{ }^{L} \mathrm{~K}$ and (d) ${ }^{D a} \mathrm{I}_{3}{ }^{D} \mathrm{~K}$ at a concentration of $8 \mathrm{mM}$ in neutral water. (b,e)

The section profiles obtained from NanoScope Analysis (Bruker) giving the height variation along the fibril axis and the pitch. (c,f) FiberApp height autocorrelation function (ACF) defining the pitch 
(periodicity) of twisted fibrils with statistical significance.
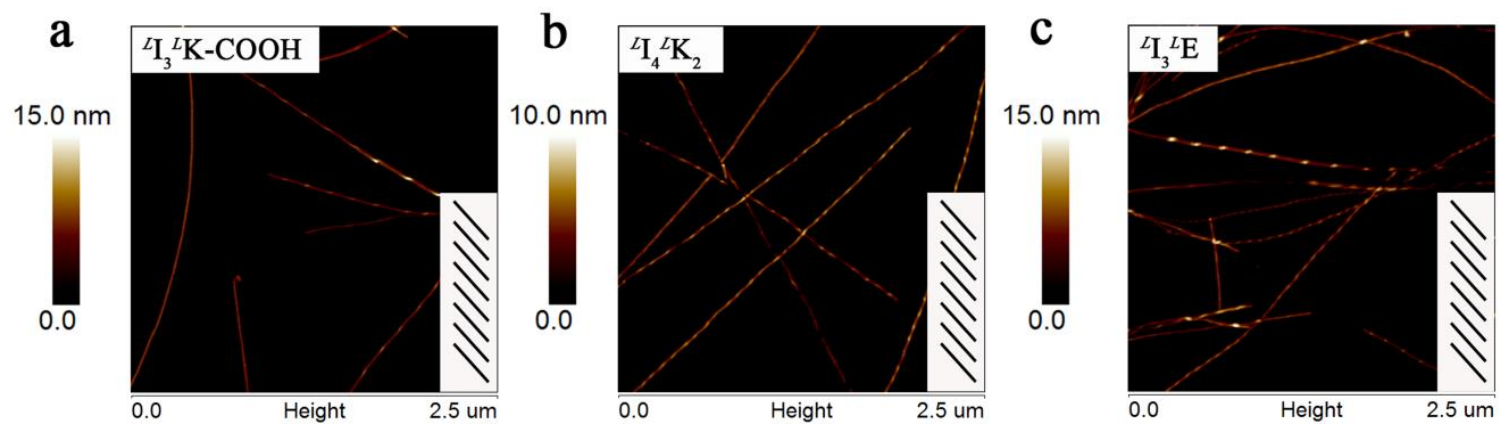

Figure 5. AFM images of (a) ${ }^{L} \mathrm{I}_{3}{ }^{L} \mathrm{~K}-\mathrm{COOH}$, (b) ${ }^{{ }^{L}} \mathrm{I}_{4}{ }^{L} \mathrm{~K}_{2}$, and (c) ${ }^{{ }^{L}} \mathrm{I}_{3}{ }^{L} \mathrm{E}$ fibrils formed at a concentration of $8 \mathrm{mM}$. Because ${ }^{{ }^{L} \mathrm{I}_{3}}{ }^{L} \mathrm{~K}-\mathrm{COOH}$ showed very low solubility in neutral water, the peptide solution (8 $\mathrm{mM}$ ) was prepared at $\mathrm{pH}$ 2.0. The $\mathrm{pH}$ value of the other two peptide solutions was 7.0. Their MS and HPLC profiles are given in Figure S6, indicating their correct sequences and high purities.

Overall, when changing the chirality of Ile from $L$-Ile to $L$-aIle and $D$-Ile whilst remaining the chirality of Lys as $L$-Lys, the twisted nanofibrils formed by ${ }^{L} \mathrm{I}_{3}{ }^{L} \mathrm{~K},{ }^{L a} \mathrm{I}_{3}{ }^{L} \mathrm{~K}$, and ${ }^{D} \mathrm{I}_{3}{ }^{L} \mathrm{~K}$ remained left-handed (Figures $2 \mathrm{a}, 2 \mathrm{~b}, 4 \mathrm{a}$, and 3a). Upon varying the chirality of Lys from $L$-Lys to $D$-Lys, a handedness inversion occurred and the ${ }^{L} \mathrm{I}_{3}{ }^{D} \mathrm{~K},{ }^{D a} \mathrm{I}_{3}{ }^{D} \mathrm{~K}$, and ${ }^{D} \mathrm{I}_{3}{ }^{D} \mathrm{~K}$ nanofibrils were right-handed twisted (Figures $2 \mathrm{e}, 2 \mathrm{f}, 4 \mathrm{~d}$, and $3 \mathrm{~d}$ ). These results indicated that for short amphiphilic $\mathrm{I}_{3} \mathrm{~K}$ peptides, the handedness of their supramolecular assemblies (nanofibrils) was dictated by the molecular chirality of the C-terminal hydrophilic Lys while the chirality of hydrophobic Ile residues had little effect. In fact, the observation was general for this kind of amphiphilic peptides. For example, ${ }^{L} \mathrm{I}_{3}{ }^{L} \mathrm{~K}-\mathrm{COOH}$ with an uncapped C-terminus, ${ }^{L} \mathrm{I}_{4}{ }^{L} \mathrm{~K}_{2}$ with two positively charged Lys residues at the 
C-terminus, and ${ }^{L} \mathrm{I}_{3}{ }^{L} \mathrm{E}$ with a negatively charged Glu residue at the C-terminus were all observed to form left-handed twisted nanofibrils (Figure 5). Furthermore, the handedness of the twisted fibrils remained unchanged at lower and higher $\mathrm{pH}$ values and we did not observe the handedness inversion due to $\mathrm{pH}$ variation. For example, ${ }^{L} \mathrm{I}_{3}{ }^{L} \mathrm{~K}$ or ${ }^{L_{1}}{ }_{3}{ }^{D}$ nanofibrils were still left- or right-handed twisted at $\mathrm{pH} 3.0$ and $\mathrm{pH} 9.0$, although some shorter fibril fragments and bundles of fibrils were observed at pH 9.0 (Figure S7). 

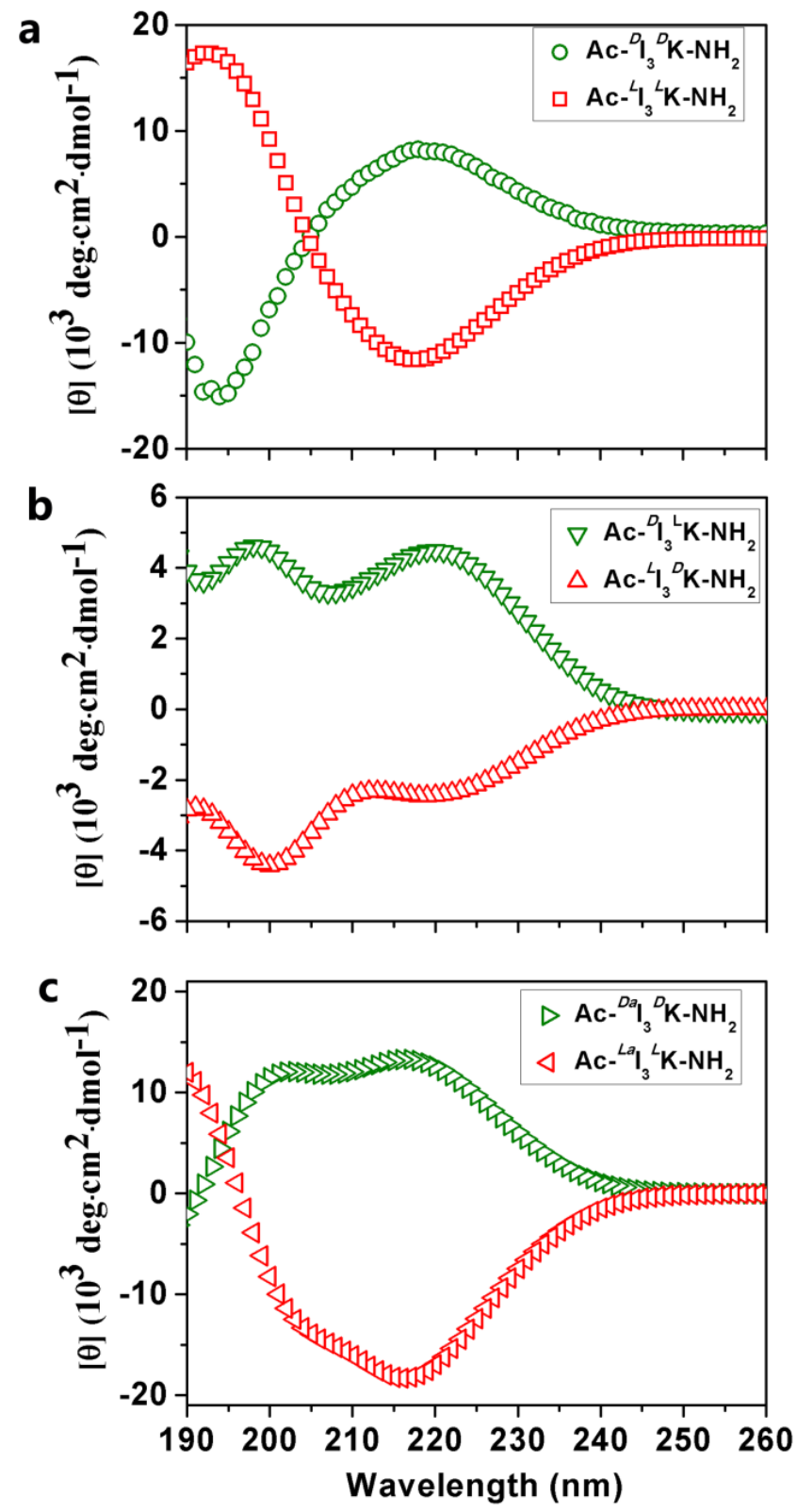

Figure 6. CD spectra of (a) ${ }^{L} \mathrm{I}_{3}{ }^{L} \mathrm{~K}$ and ${ }^{D} \mathrm{I}_{3}{ }^{D} \mathrm{~K}$, (b) ${ }^{D} \mathrm{I}_{3}{ }^{L} \mathrm{~K}$ and ${ }^{L} \mathrm{I}_{3}{ }^{D} \mathrm{~K}$, and (c) ${ }^{L a} \mathrm{I}_{3}{ }^{L} \mathrm{~K}$ and ${ }^{D a} \mathrm{I}_{3}{ }^{D} \mathrm{~K}$ at a concentration of $8 \mathrm{mM}$ in neutral water.

Far-ultraviolet circular dichroism (Far-UV CD) is not only capable of assigning the secondary structures of peptides, but is also able to assess the chirality of supramolecular interactions (e.g. hydrogen bonding). As shown in Figure 6a, the CD spectrum of ${ }^{{ }^{2}}{ }_{3}{ }^{L} \mathrm{~K}$ 
showed a maximum at $193 \mathrm{~nm}$ and a minimum at $217 \mathrm{~nm}$ (sign: +-), indicative of the formation of $\beta$-sheet secondary structures. The CD curve of ${ }^{D} \mathrm{I}_{3}{ }^{D} \mathrm{~K}$ was the perfect mirror image of that of ${ }^{L} \mathrm{I}_{3}{ }^{L} \mathrm{~K}$, with a minimum at $193 \mathrm{~nm}$ and a maximum at $217 \mathrm{~nm}$ (sign: -+), indicating chirality inversion in hydrogen bonding interactions. These findings were highly consistent with the results from AFM measurements, as well as the ones from ThT binding assays. In addition, Fourier transform infrared spectroscopy (FTIR) measurements also indicated the predominance of $\beta$-sheet conformations from the two peptide enantiomers by displaying a strong amide I band at $\sim 1620 \mathrm{~cm}^{-1}$ (Figure S8).

For the pair of ${ }^{D} \mathrm{I}_{3}{ }^{L} \mathrm{~K}$ and ${ }^{L} \mathrm{I}_{3}{ }^{D} \mathrm{~K}$ enantiomers, the $\mathrm{CD}$ spectra were also in a mirror-image relationship to each other (Figure 6b). ${ }^{D} \mathrm{I}_{3}{ }^{L} \mathrm{~K}$ exhibited a positive peak around $220 \mathrm{~nm}$ while $\mathrm{Ac}-{ }^{L} \mathrm{I}_{3}{ }^{D} \mathrm{~K}$ had a negative one around $220 \mathrm{~nm}$, indicating the formation of $\beta$-sheets but with opposite chirality. However, the two characteristic $\beta$-sheet peaks were weaker in intensity than those of other four peptide isomers. also consistent with the results from ThT binding assays (Figure S3). The results suggest that less peptide molecules participated in $\beta$-sheet hydrogen bonding from the two heterochiral peptides. As a result, there should be considerable peptide monomers in random coil conformations, as evident from the occurrence of a strong positive peak and a strong negative peak around $200 \mathrm{~nm}$ for ${ }^{D} \mathrm{I}_{3}{ }^{L} \mathrm{~K}$ and ${ }^{L_{3}}{ }^{D} \mathrm{~K}$, respectively (Figure 6b). After dialysis against Milli-Q water for 2 days using a dialysis bag (molecular weight cutoff: $3500 \mathrm{Da}$ ), 
the effect of peptide monomers on the CD signal could be markedly alleviated, presumably due to their dynamic equilibrium with the self-assembled fibrils and subsequent monomer removal (Figure S9a). As a result of the contribution of the random coil conformation of peptide monomers, FTIR measurements showed significant blue-shifting of the main amide I peak from $\sim 1620$ to $\sim 1635 \mathrm{~cm}^{-1}$ (Figure S8).

For the pair of ${ }^{L a} \mathrm{I}_{3}{ }^{L} \mathrm{~K}$ and ${ }^{D a} \mathrm{I}_{3}{ }^{D} \mathrm{~K}$, the $\mathrm{CD}$ spectra had an imperfect mirror-image relationship to each other (Figure $6 \mathrm{c}$ ). ${ }^{D a} \mathrm{I}_{3}{ }^{D} \mathrm{~K}$ showed a positive peak at $217 \mathrm{~nm}$ whose absolute molar ellipticity was nearly identical to those of ${ }^{L_{3}}{ }_{3} \mathrm{~K}$ and ${ }^{D} \mathrm{I}_{3}{ }^{D} \mathrm{~K}$. The enantiomer ${ }^{L a} \mathrm{I}_{3}{ }^{L} \mathrm{~K}$ had a negative peak at $217 \mathrm{~nm}$, but its absolute molar ellipticity was markedly higher than that of ${ }^{D a} \mathrm{I}_{3}{ }^{D} \mathrm{~K}$. Such a difference can be ascribed to the strongest $\beta$-sheet hydrogen bonding of ${ }^{L a} \mathrm{I}_{3}{ }^{L} \mathrm{~K}$, which has been demonstrated by the above ThT binding assay (Figure S3). Although FTIR measurements indicated the dominance of $\beta$-sheet conformations for the two peptide enantiomers (Figure S8), there were a negative CD peak and a positive one at $\sim 202 \mathrm{~nm}$ for ${ }^{L a} \mathrm{I}_{3}{ }^{L} \mathrm{~K}$ and ${ }^{D a} \mathrm{I}_{3}{ }^{D} \mathrm{~K}$, respectively (Figure 6c). They are most likely to arise from peptide monomers, because the two peaks almost completely disappeared after dialysis against Milli-Q water for 2 days (Figure S9b).

Although the helical handedness of $\mathrm{I}_{3} \mathrm{~K}$ nanofibrils was controlled by the molecular chirality of the C-terminal Lys residue, the chirality of their far-UV CD signals, which revealed the main characteristic of secondary structures, seemed to be determined by the 
chirality of the hydrophobic Ile residue. For example, the ${ }^{D} \mathrm{I}_{3}{ }^{L} \mathrm{~K}$ nanofibrils were left-handed while their characteristic $\beta$-sheet peak at $\sim 220 \mathrm{~nm}$ was positive, similar to ${ }^{D} \mathrm{I}_{3}{ }^{D} \mathrm{~K}$ and ${ }^{D a} \mathrm{I}_{3}{ }^{D} \mathrm{~K}$. The nanofibrils formed by the two latter peptides were right-handed twisted. In contrast, ${ }^{{ }_{1}}{ }_{3}{ }^{D} \mathrm{~K}$ displayed a negative $\mathrm{CD}$ peak at $\sim 220 \mathrm{~nm}$, similar to ${ }^{{ }^{L}} \mathrm{I}_{3}{ }^{L} \mathrm{~K}$ and ${ }^{L a} \mathrm{I}_{3}{ }^{L} \mathrm{~K}$.

In order to understand the molecular basis of the handedness of the self-assembled peptide nanofibrils, we performed molecular dynamics (MD) simulation to study their twisting propensity. According to the above spectroscopic results, the peptides were assumed to take $\beta$-strand conformations. As shown in Figure $7 \mathrm{a}$, the $\beta$-strand conformation of ${ }^{L_{3}}{ }_{3} \mathrm{~K}$ was a mirror image of the ${ }^{D} \mathrm{I}_{3}{ }^{D} \mathrm{~K}$ conformation. When constructing the initial molecular models, the peptide molecules were aligned along the direction of hydrogen bonding between backbones and their side chains were maximally in contact so that there were a sufficient number of intermolecular hydrogen bonds. For this pair of peptides, the intermolecular alignment was anti-parallel and there was no residue shift between adjacent strands (Figure 7b). Likewise, ${ }^{L a} \mathrm{I}_{3}{ }^{L} \mathrm{~K}$ and ${ }^{D a} \mathrm{I}_{3}{ }^{D} \mathrm{~K}$ were built in the same way, given that they have the same backbone configuration as ${ }_{\mathrm{I}_{3}}^{{ }^{L} \mathrm{~K}}$ and ${ }^{D} \mathrm{I}_{3}{ }^{D} \mathrm{~K}$, respectively (Figure 7b). For ${ }^{L} \mathrm{I}_{3}{ }^{D} \mathrm{~K}$ and ${ }^{D} \mathrm{I}_{3}{ }^{L} \mathrm{~K}$, Lys4 has a configuration with opposite chirality around the $\mathrm{C} \alpha$ atom compared with the other three Ile residues, resulting in a non-typical strand conformation in which either the position of the side chain of Lys4 
residue or the torsional angles pertinent of Lys4 would be changed. When keeping the position of the Lys side chain unchanged, the amide group (or the peptide plane) between Ile3 and Lys 4 residues needed to rotate along the N-C $\alpha$ bond of Lys by $180^{\circ}$, as shown in Figure 7a. This non-typical backbone conformation was supposed to a non-typical inter-strand alignment. When the peptides were aligned anti-parallel to each other, the amide group (or the peptide plane) between the acetyl group and Ile1 also had torotate along the $\mathrm{C} \alpha-\mathrm{C}$ bond of Ile1 by $180^{\circ}$ to form complementary hydrogen-bonding with the ones between Ile3 and Lys4 of adjacent strands (Figure 7b). Consequently, the orientation of hydrogen-bonding at the two termini was changed to an opposite direction, and there was one residue shift in this alignment (Figure 7b).

MD simulations showed that the $\beta$-sheets formed by ${ }^{{ }}{ }_{3}{ }^{L} \mathrm{~K}$ and ${ }^{D} \mathrm{I}_{3}{ }^{D} \mathrm{~K}$ exhibited a strong propensity to twist in left-handed and right-handed directions, respectively. ${ }^{L a}{ }_{3}{ }_{3} \mathrm{~K}$ and ${ }^{D a} \mathrm{I}_{3}{ }^{D} \mathrm{~K}$ showed similar results. In contrast, ${ }^{L} \mathrm{I}_{3}{ }^{D} \mathrm{~K}$ and ${ }^{D} \mathrm{I}_{3}{ }^{L} \mathrm{~K}$, which align with non-typical hydrogen-bonding orientation, exhibited right-handed and left-handed directions, respectively (Figure 7b). 


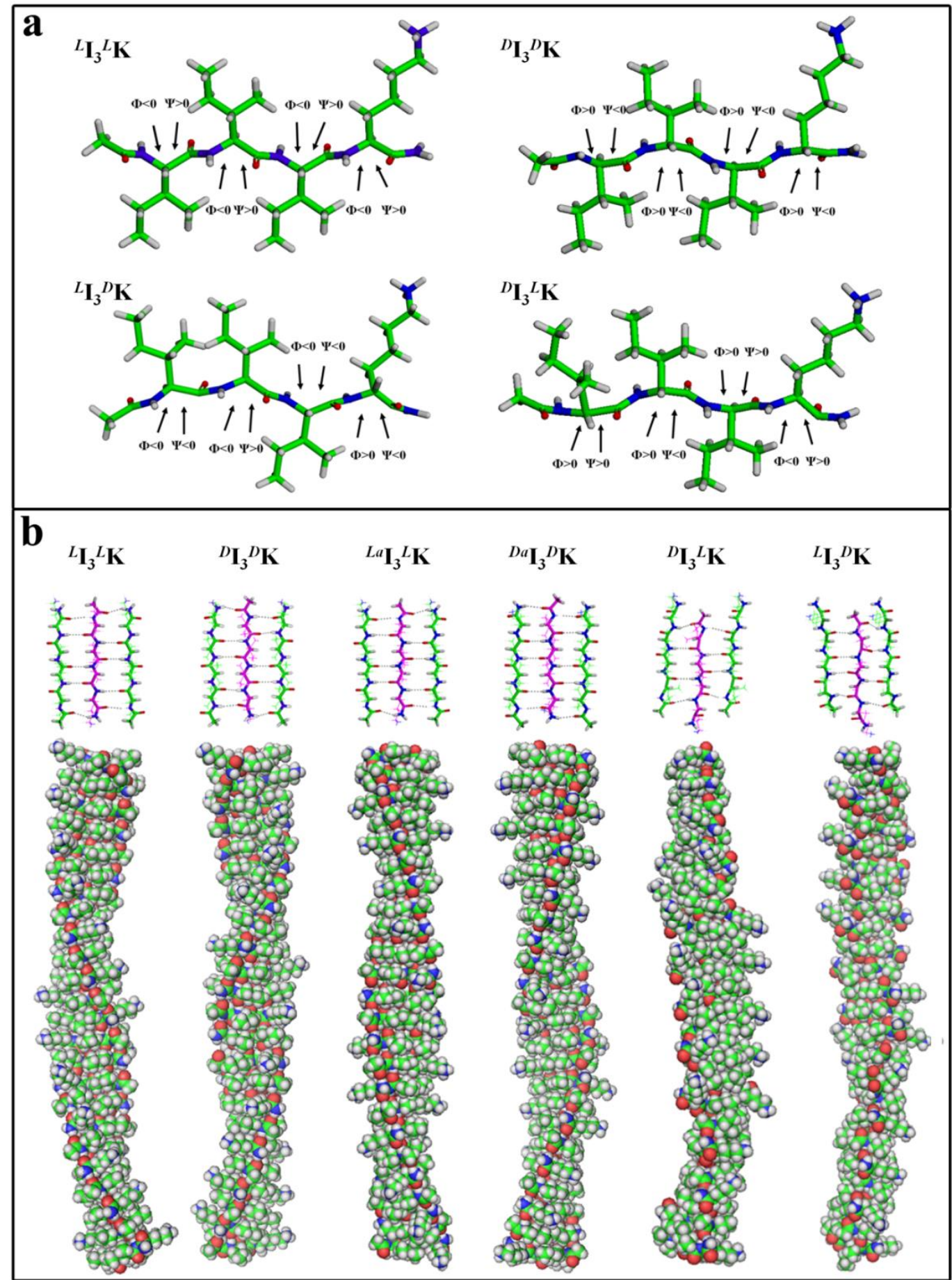

Figure 7. (a) Geometry of ${ }^{L} \mathrm{I}_{3}{ }^{L} \mathrm{~K},{ }^{D} \mathrm{I}_{3}{ }^{D} \mathrm{~K},{ }^{D} \mathrm{I}_{3}{ }^{L} \mathrm{~K}$, and ${ }^{L} \mathrm{I}_{3}{ }^{D} \mathrm{~K} \beta$-strands. (b) Inter-strand packing modes and the handedness of the self-assembled single $\beta$-sheet layers of three pairs of $\mathrm{I}_{3} \mathrm{~K}$ enantiomers.

\section{CONCLUSIONS}


To establish how molecular chirality affects self-assembly, we have designed and synthesized three pairs of peptide enantiomers, ${ }^{L} \mathrm{I}_{3}{ }^{L} \mathrm{~K}$ and ${ }^{D} \mathrm{I}_{3}{ }^{D} \mathrm{~K},{ }^{L} \mathrm{I}_{3}{ }^{D} \mathrm{~K}$ and ${ }^{D} \mathrm{I}_{3}{ }^{L} \mathrm{~K}$, and ${ }^{L a} \mathrm{I}_{3}{ }^{L} \mathrm{~K}$ and ${ }^{D a} \mathrm{I}_{3}{ }^{D} \mathrm{~K}$. The self-assembled nanofibrils from these short amphiphilic peptides illustrate the key role of the molecular chirality of constituent amino acids in controlling their morphological handedness. The handedness of the helical nanofibrils was dictated by the chirality of the hydrophilic Lys head at the C-terminus, i.e., the ${ }^{L} \mathrm{I}_{3}{ }^{L} \mathrm{~K},{ }^{L a} \mathrm{I}_{3}{ }^{L} \mathrm{~K}$, and ${ }^{D} \mathrm{I}_{3}{ }^{L} \mathrm{~K}$ nanofibrils were left-handed twisted while the ${ }^{L} \mathrm{I}_{3}{ }^{D} \mathrm{~K},{ }^{D a} \mathrm{I}_{3}{ }^{D} \mathrm{~K}$, and ${ }^{D} \mathrm{I}_{3}{ }^{D} \mathrm{~K}$ ones were right-handed twisted. However, the morphological handedness could not be changed by altering the molecular chirality of hydrophobic Ile residues. In contrast, the sign of their characteristic CD signals indicating secondary structures was determined by the chirality of hydrophobic Ile residues, i.e., the assemblies of ${ }^{{ }^{L}} \mathrm{I}_{3}{ }^{L} \mathrm{~K},{ }^{L a} \mathrm{I}_{3}{ }^{L} \mathrm{~K}$, and ${ }^{{ }^{L}} \mathrm{I}_{3}{ }^{D} \mathrm{~K}$ showed a negative $\beta$-sheet peak at around $220 \mathrm{~nm}$, while those of ${ }^{D} \mathrm{I}_{3}{ }^{D} \mathrm{~K},{ }^{D a} \mathrm{I}_{3}{ }^{D} \mathrm{~K}$, and ${ }^{D} \mathrm{I}_{3}{ }^{L} \mathrm{~K}$ showed a positive $\beta$-sheet peak at around $220 \mathrm{~nm}$, and these two peptide sets were mirror-images, respectively. The handedness development from molecular chirality to supramolecular handedness was also examined in MD simulations, in which the $\beta$-sheets formed by ${ }^{L} \mathrm{I}_{3}{ }^{L} \mathrm{~K}$, ${ }^{L a} \mathrm{I}_{3}{ }^{L} \mathrm{~K}$ and ${ }^{D} \mathrm{I}_{3}{ }^{L} \mathrm{~K}$ exhibited a propensity to twist in a left-handed direction, whilst the ones of ${ }^{D} \mathrm{I}_{3}{ }^{D} \mathrm{~K},{ }^{D a} \mathrm{I}_{3}{ }^{D} \mathrm{~K}$ and ${ }^{L} \mathrm{I}_{3}{ }^{D} \mathrm{~K}$ showed a right-handed twisting orientation, in good agreement with experimental observations.

\section{EXPERIMENTAL SECTION}


Materials. Peptides used in this study were synthesized on a CEM Liberty microwave synthesizer based on Fmoc solid-phase chemistry. The use of Rink amide MBHA resin and Wang resin allowed their C-termini to be capped (amidation) and uncapped, respectively. For all the peptides used, their N-termini were capped with acetic anhydride prior to cleavage from the resin. The detailed synthesis and purification procedures have been described in our previous work. ${ }^{31,32}$ The final peptide products were analyzed using RP-HPLC and MALDI TOF mass spectrometer. Water used in all experiments was from a Millipore Milli-Q Biocell system, with a minimum resistivity of $18.2 \mathrm{M} \Omega \cdot \mathrm{cm}$.

Peptide Self-Assembly. The peptides were first dispersed in hexafluoroisopropanol (HFIP). After removal of HFIP by evaporation overnight, Milli-Q water was introduced. After sonication for 10 minutes, the peptides were completely dissolved in Milli-Q water, resulting in peptide solutions with a final concentration of $8 \mathrm{mM}$. The solution $\mathrm{pH}$ was slightly adjusted to $7.0 \pm 0.1$ by using dilute $\mathrm{NaOH}$ and then incubated at room temperature for 10 days without any agitation before further characterization.

Atomic Force Microscopy (AFM). 10-20 $\mu \mathrm{L}$ of the aged peptide solution was deposited onto a freshly cleaved mica sheet. After adsorption for less than 1 minute, the solution on the mica surface was dried by gently purging with $\mathrm{N}_{2}$ for about 30 seconds. Samples were imaged on a commercial MultiMode Scanning Probe Microscope with a NanoScope IVa controller (Digital Instruments, Santa Barbara, CA) in tapping mode. 
AFM height images (512 $\times 512$ pixels) were acquired at a scan rate of $1.0 \mathrm{~Hz}$ and a scan angle of $0^{\circ}$ using TESP silicon tips $(320 \mathrm{kHz}, 42 \mathrm{~N} / \mathrm{m})$. After the 2 nd order flattening, all height images were directly analyzed using NanoScope Analysis software (version 1.40, Bruker) to obtain section profiles along the fibril axis. By using open-source software FiberApp (www.fsm.ethz.ch), many twisted fibrils were tracked and analyzed with height autocorrelation function (ACF) to obtain the pitch values with statistical significance.

Circular Dichroism (CD) Spectroscopy. CD measurements were performed on a MOS-450 spectrometer (Bio-logic, France) using a $0.1 \mathrm{~mm}$ path-length quartz cell at room temperature. The CD spectra were recorded with wavelength scanning from 260 to $190 \mathrm{~nm}$. The scan speed was $60 \mathrm{~nm} \mathrm{~min}{ }^{-1}$ and the bandwidth was $0.5 \mathrm{~nm}$ for every sample. The solvent background was subtracted using the Biokine software. The presented CD signals were expressed as [ $\theta]\left(10^{3} \mathrm{deg} \mathrm{cm}^{2} \mathrm{dmol}^{-1}\right)$ or millidegree versus wavelength.

Molecular Dynamics (MD) Methods. MD calculations were performed using the GROMACS 4.5.5 software package. ${ }^{39}$ Peptide interactions were modelled by the CHARMM force field. ${ }^{40}$ Solvent effects were taken into account by the GBSA implicit-solvent model. ${ }^{41}$ No cutoff and a time step of 1 fs was used for both the electrostatic interactions and Lennard-Jones interactions. The system temperature was initially set to $10 \mathrm{~K}$ and then increased to $203 \mathrm{~K}$. After $500 \mathrm{ps}$ equilibration, the temperature was raised to $293 \mathrm{~K}$ and kept constant for at least $1 \mathrm{~ns}$ using the Berendsen thermostat with 
a time constant of $0.1 \mathrm{ps} .{ }^{42}$ 


\section{ASSOCIATED CONTENT}

\section{Supporting Information}

Figures S1-S8 including RP-HPLC profiles and MALDI-TOF mass spectra of peptides, fluorescence emission spectra of ThT in the absence and presence of peptides, TEM and SEM images of peptide self-assemblies, AFM images of the peptide fibrils formed at $\mathrm{pH} 3.0$ and pH 9.0, FTIR spectra of peptides, and CD spectra of peptides after dialysis. This material is available free of charge via the Internet at http://pubs.acs.org.

\section{AUTHOR INFORMATION}

\section{Corresponding Authors}

E-mail: jqwang@upc.edu.cn (J.Q.W.); xuh@upc.edu.cn (X.H.)

\section{Notes}

The authors declare no competing financial interest.

\section{ACKNOWLEDGEMENTS}

We thank Robert K. Thomas at the University of Oxford and Henry Cox and Thomas Waigh at the University of Manchester for critical reading of the manuscript. This work was supported by the National Natural Science Foundation of China under grant numbers 21373270 and 21573287, the Fundamental Research Funds for the Central Universities in China (14CX06095A) and the UK Engineering and Physical Science Research Council (EPSRC) under EP/F062966/1 and EPSRC and Innovate UK under KTP008143 


\section{REFERENCES}

(1) Hegstrom, R. A.; Kondepudi, D. K. The Handedness of the Universe. Sci. Am. 1990, 262, 108-115.

(2) Neville, A. C. Biology of Fibrous Composites: Development Beyond the Cell Membrane; Cambridge University Press: Cambridge, U.K., 1993.

(3) Mason, S. F. Origins of Biomolecular Handedness. Nature 1984, 311, 19-23.

(4) Feringa, B. L.; van Delden, R. A. Absolute Asymmetric Synthesis: The Origin, Control, and Amplification of Chirality. Angew. Chem., Int. Ed. 1999, 38, 3418-3438.

(5) Brown, N. A.; Wolpert, L. The Development of Handedness in Left/Right Asymmetry. Development 1990, 109, 1-9

(6) Richardson, J. S. The Anatomy and Taxonomy of Protein Structure. Adv. Protein Chem. 1981, 34, $167-229$.

(7) Chou, K.-C.; Nemethy, G.; Scheraga, H. A. Energetics of Interactions of Regular Structural Elements in Proteins. Acc. Chem. Res. 1990, 23, 134-141.

(8) Shamovsky, I. L.; Ross, G. M.; Riopelle, R. J. Theoretical Studies on the Origin of $\beta$-Sheet Twisting. J. Phys. Chem. B 2000, 104, 11296-11307.

(9) Aggeli, A.; Nyrkova, I. A.; Bell, M.; Harding, R.; Carrick, L.; McLeish, T. C. B.; Semenov, A. N.; Boden, N. Hierarchical Self-assembly of Chiral Rod-like Molecules as a Model for Peptide $\beta$-sheet Tapes, Ribbons, Fibrils, and Fibers. Proc. Natl. Acad. Sci. U. S. A. 2001, 98, 11857-11862.

(10) Jiménez, J. L., Nettleton, E. J., Bouchard, M., Robinson, C. V., Dobson, C. M., Saibil, H. R. The Protofilament Structure of Insulin Amyloid Fibrils. Proc. Natl. Acad. Sci. U.S.A. 2002, 99, 9196-9201. 
(11) Wadai, H.; Yamaguchi, K.; Takahashi, S.; Kanno, T.; Kawai, T.; Naiki, H.; Goto, Y. Stereospecific Amyloid-Like Fibrils Formation by a Peptide Fragment of $\beta_{2}$-Microglobulin. Biochemistry 2005, 44, $157-164$.

(12) Harper, J. D.; Lieber, C. M.; Lansbury, P. T. Jr. Atomic Force Microscopic Imaging of Seeded Fibril Formation and Fibril Branching by the Alzheimer's Disease Amyloid- $\beta$ Protein. Chem. Biol. 1997, 4, 951-959.

(13) Rubin, N.; Perugia E.; Goldschmidt, M.; Fridkin, M.; Addadi, L. Chirality of Amyloid Suprastructures. J. Am. Chem. Soc. 2008, 130, 4602-4603.

(14) Zhang, R.; Hu, X.; Khant, H.; Ludtke, S. J.; Chiu, W.; Schmid, M. F.; Frieden, C.; Lee, J. -M. Interprotofilament Interactions between Alzheimer's $A \beta_{1-42}$ Peptides in Amyloid Fibrils Revealed by CryoEM. Proc. Natl. Acad. Sci. U.S.A. 2009, 106, 4653-4658.

(15) Mizuno, N.; Baxa, U.; Steven, A. C. Structural Dependence of HET-s Amyloid Fibril Infectivity Assessed by Cryoelectron Microscopy. Proc. Natl. Acad. Sci. U.S.A. 2011, 108, 3252-3257.

(16) Bedrood, S.; Li, Y.; Isas, J. M.; Hegde, B. G.; Baxa, U.; Haworth, I. S.; Langen, R. Fibril Structure of Human Islet Amyloid Polypeptide. J. Biol. Chem. 2012, 287, 5235-5241.

(17) Schmidt, A.; Annamalai, K.; Schmidt, M.; Grigorieff, N.; Fändrich, M. Cryo-EM Reveals the Steric Zipper Structure of a Light Chain-Derived Amyloid Fibril. Proc. Natl. Acad. Sci. U. S. A. 2016, $113,6200-6205$.

(18) Koga, T.; Matsuoka, M.; Higashi, N. Structural Control of Self-Assembled Nanofibers by 
Artificial $\beta$-Sheet Peptides Composed of D- or L-Isomer. J. Am. Chem. Soc. 2005, 127, 17596-17597.

(19) Rubin, N.; Perugia E.; Wolf, S. A.; Klein, E.; Fridkin, M.; Addadi, L. Relationship between Serum Amyloid A truncated Peptide and Their Suprastructure Chirality. J. Am. Chem. Soc. 2010, 132, $4242-4248$

(20) Usov, I.; Adamcik, J.; Mezzenga, R. Polymorphism Complexity and Handedness Inversion in Serum Albumin Amyloid Fibrils. ACS Nano 2013, 7, 10465-10474.

(21) Volpatti, L. R.; Vendruscolo, M.; Dobson, C. M.; Knowles, T. P. J. A Clear View of Polymorphism, Twist, and Chirality in Amyloid Fibril Formation. ACS Nano 2013, 7, 10443-10448.

(22) Lara, C.; Reynolds, N. P.; Berryman, J.; Xu, A.; Zhang, A.; Mezzenga, R. ILQINS Hexapeptide, Identified in Lysozyme Left-handed Helical Ribbons and Nanotubes, Forms Right-Handed Helical Ribbons and Crystals. J. Am. Chem. Soc. 2014, 136, 4732-4739.

(23) Kurouski, D.; Lu, X.; Popova, L.; Wan, W.; Shanmugasundaram, M.; Stubbs, G.; Dukor, R. K.; Lednev, I. K.; Nafie, L. A. Is Supramolecular Filament Chirality the Underlying Cause of Major Morphology Differences in Amyloid Fibrils? J. Am. Chem. Soc. 2014, 136, $2302-2312$.

(24) Marchesan, S.; Easton, C. D.; Styan, K. E.; Kushkaki, F.; Waddington, L; Hartley, P. G.; Tripeptide Self-Assembled Hydrogels: Unexpected Twists of Chirality. Chem. Commun. 2012, 48, 2195-2197.

(25) Marchesan, S.; Easton, C. D.; Styan, K. E.; Waddington, L. J.; Kushkaki, F.; Goodall, L.; McLean, K. M.; Forsythe, J. S.; Hartley, P. G.; Chirality Effects at Each Amino Acid Position on Tripeptide 
Self-Assembly into Hydrogel Biomaterials. Nanoscale 2014, 6, 5172-5180.

(26) Marchesan, S.; Styan, K. E.; Easton, C. D.; Waddington, L.; Vargiu, A. V. Higher and Lower Supramolecular Orders for the Design of Self-Assembled Heterochiral Tripeptide Hydrogel Biomaterials. J. Mater. Chem. B 2015, 3, 8123-8132.

(27) Vargiu, A. V.; Iglesias, D.; Styan, K. E.; Waddington, L. J.; Easton, C. D.; Marchesan, S. Design of a Hydrophobic Tripeptide That Self-Assembles into Amphiphilic Superstructures Forming a Hydrogel Biomaterial. Chem. Commn. 2016, 52, 5912-5915.

(28) Luo, Z.; Wang, S.; Zhang, S. Fabrication of Self-Assembling D-Form Peptide Nanofiber Scaffold d-EAK16 for Rapid Hemostasis. Biomaterials 2011, 32, 2013-2020

(29) Fu, Y.; Li, B.; Huang, Z.; Li, Y.; Yang, Y. Terminal Is Important for the Helicity of the Self-Assemblies of Dipeptides Derived from Alanine. Langmuir 2013, 29, 6013-6017.

(30) Lin, S.; Li, Y.; Li, B.; Yang, Y. Control of the Handedness of Self-Assemblies of Dipeptides by the Chirality of Phenylalanine and Steric Hindrance of Phenylglycine. Langmuir 2016, 32, 7420-7426. (31) Xu, H.; Wang, Y.; Wang, S.; Zhou, P.; Shan, H.; Zhao, X.; Lu, J. R. Twisted Nanotubes Formed from Ultrashort Amphiphilic Peptide $\mathrm{I}_{3} \mathrm{~K}$ and Their Templating for the Fabrication of Silica Nanotubes. Chem. Mater. 2010, 22, 5165-5173.

(32) Han, S.; Cao, S.; Wang, Y.; Wang, J.; Xia, D.; Xu, H.; Zhao, X.; Lu, J. R. Self-Assembly of Short Peptide Amphiphiles: The Cooperative Effect of Hydrophobic Interaction and Hydrogen Bonding.

Chem. Eur. J. 2011, 17, 13095-13102. 
(33) Levine, H. Thioflavine T Interaction with Synthetic Alzheimer's Disease $\beta$-Amyloid Peptides:

Detection of Amyloid Aggregation in Solution. Protein Sci. 1993, 2, 404-410.

(34) Biancalana, M.; Makabe, K.; Koide, A.; Koide, S. Molecular Mechanism of Thioflavin-T Binding to the Surface of $\beta$-Rich Peptide Self-Assemblies. J. Mol. Biol. 2009, 385, 1052-1063.

(35) Usov, I.; Mezzenga, R. FiberApp: An Open-Source Software for Tracking and Analyzing Polymers, Filaments, Biomacromolecules, and Fibrous Objects. Macromolecules 2015, 48, 1269-1280.

(36) Deng, M.; Zhang, L.; Jiang, Y.; Liu, M. Role of Achiral Nucleobases in Multicomponent Chiral Self-Assembly: Purine-Triggered Helix and Chiral Transfer. Angew. Chem., Int. Ed. 2016, 55, 15062-15066.

(37) Adamcik, J.; Jung, J. -M.; Flakowski, J.; De Los Rios, P.; Dietler, G.; Mezzenga, R. Understanding Amyloid Aggregation by Statistical Analysis of Atomic Force Microscopy Images. Nat. Nanotechnol. 2010, 5, 423-428.

(38) Ziserman, L.; Lee, H. -Y.; Raghavan, S. R.; Mor, A.; Danino, D. Unraveling the Mechanism of Nanotube Formation by Chiral Self-Assembly of Amphiphiles. J. Am. Chem. Soc. 2011, 133, 2511-2517.

(39) Van der Spoel, D.; Lindahl, E.; Hess, B.; Groenhof, G.; Mark, A. E.; Berendsen, H. J. C. Gromacs: Fast, Flexible, and Free. J. Comput. Chem. 2005, 26, 1701-1718.

(40) Brooks, B. R.; Bruccoleri, R. E.; Olafson, B. D.; States, D. J.; Swaminathan, S.; Karplus, M. 
CHARMM: A Program for Macromolecular Energy, Minimization, and Dynamics Calculations. $J$.

Comput. Chem. 1983, 4, 187-217.

(41) Onufriev, A.; Bashford, D.; Case, D. A. Exploring Protein Native States and Large-Scale Conformational Changes with a Modified Generalized Born Model. Proteins: Struct., Funct., Bioinf.

2004, 55, 383-394.

(42) Berendsen, H. J. C.; Postma, J. P. M.; van Gunsteren, W. F.; DiNola, A.; Haak, J. R. Molecular Dynamics with Coupling to an External Bath. J. Chem. Phys. 1984, 81, 3684-3690. 
SUPPORTING INFORMATION

\section{Left or Right: How Does Amino Acid Chirality Affect the Handedness of Nanostructures Self-Assembled from Short Amphiphilic Peptides?}

Meng Wang, ${ }^{\dagger}$ Peng Zhou, ${ }^{\dagger}$ Jiqian Wang, ${ }^{\dagger} * *$ Yurong Zhao, ${ }^{\dagger}$ Hongchao Ma, ${ }^{\dagger}$ Jian R. Lu ${ }^{\ddagger}$ and Hai $\mathrm{Xu}^{\dagger+*}$

†State Key Laboratory of Heavy Oil Processing and Centre for Bioengineering and Biotechnology, China University of Petroleum (East China), 66 Changjiang West Road, Qingdao 266555, China

*Biological Physics Laboratory, School of Physics and Astronomy, University of Manchester, Schuster Building, Manchester M13 9PL, UK 

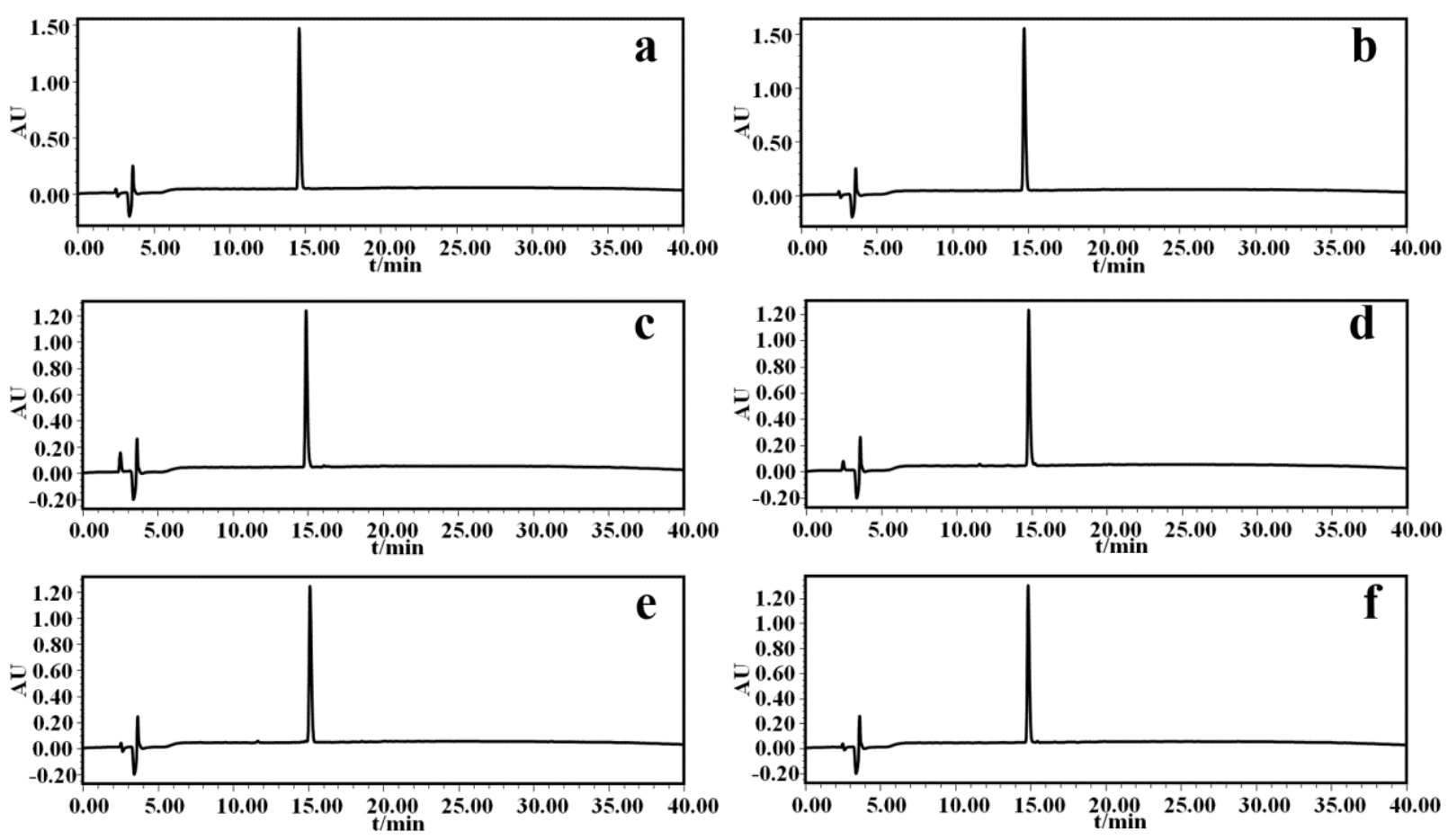

Figure S1. RP-HPLC profiles of (a) ${ }^{L} \mathrm{I}_{3}{ }^{L} \mathrm{~K}$, (b) ${ }^{D} \mathrm{I}_{3}{ }^{D} \mathrm{~K}$, (c) ${ }^{D} \mathrm{I}_{3}{ }^{L} \mathrm{~K}$, (d) ${ }^{{ }^{L} \mathrm{I}_{3}}{ }^{D} \mathrm{~K}$, (e) ${ }^{L a} \mathrm{I}_{3}{ }^{L} \mathrm{~K}$, and (f) ${ }^{D a} \mathrm{I}_{3}{ }^{D} \mathrm{~K}$.

The experimental condition for the HPLC analysis is as follows: Eluent A, $0.1 \%$ TFA in water, and eluent $\mathrm{B}, 0.1 \% \mathrm{TFA}$ in acetonitrile. Isocratic elution of $0 \rightarrow 1 \mathrm{~min}, 95 \%$ eluent $A$ and $5 \%$ eluent $B ; 1 \rightarrow 40$ min, a linear gradient elution of eluent $A$ from $95 \% \rightarrow 5 \%$ and eluent B from $5 \%$ to $95 \% ; 40 \rightarrow 45$ min, a linear elution to $95 \%$ eluent A and $5 \%$ eluent B to restore the system. UV detector set at $214 \mathrm{~nm}$; eluent flow rate of $0.6 \mathrm{~mL} / \mathrm{min}$; column, RP-C18, $4.6 \mathrm{~mm} \times 150 \mathrm{~mm}$. The measurements were performed on Waters 2695 Alliance HPLC system at a temperature of $25^{\circ} \mathrm{C}$. 

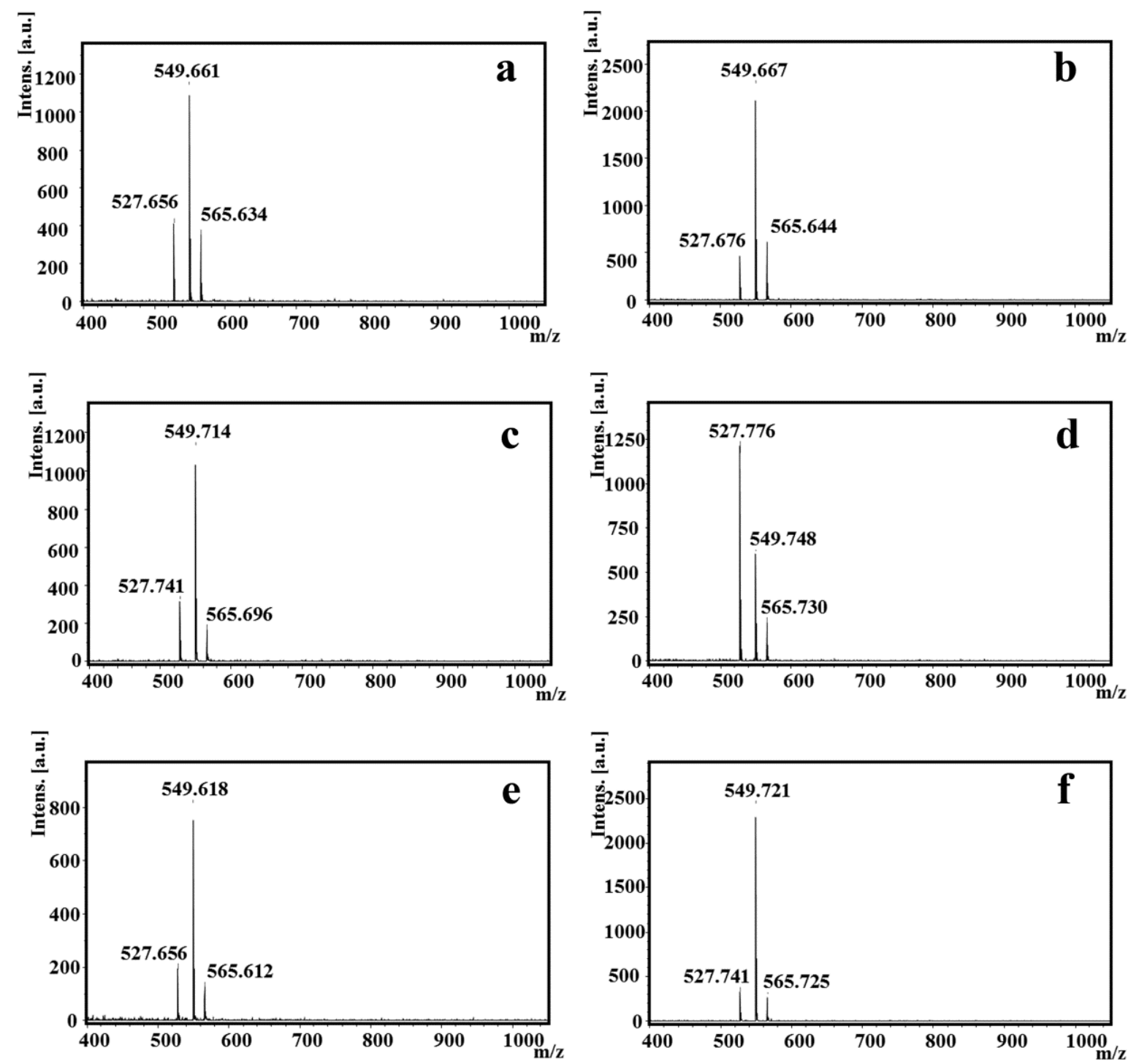

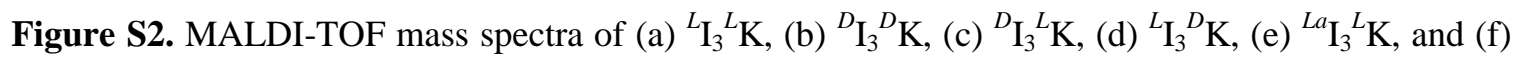
${ }^{D a} \mathrm{I}_{3}{ }^{D} \mathrm{~K}$.

The mass measurements were performed on a Bruker Microflex LRF (MALDI mass spectrometer, and $\alpha$-cyano-4-hydroxycinnamic acid (HCCA) was used as the matrix. The peptides and HCCA were dissolved in the mixture of acetonitrile and water (3:7, v/v) containing $0.1 \%$ trifluoroacetic acid (TFA). Around $1 \mu \mathrm{L}$ of the resulting solution was 
placed on a metal sample plate and then allowed to air-dry at room temperature. Mass spectra were acquired in reflection positive mode and using an acceleration voltage of 20 $\mathrm{kV}$. External mass calibration was achieved using a standard peptide mixture. 


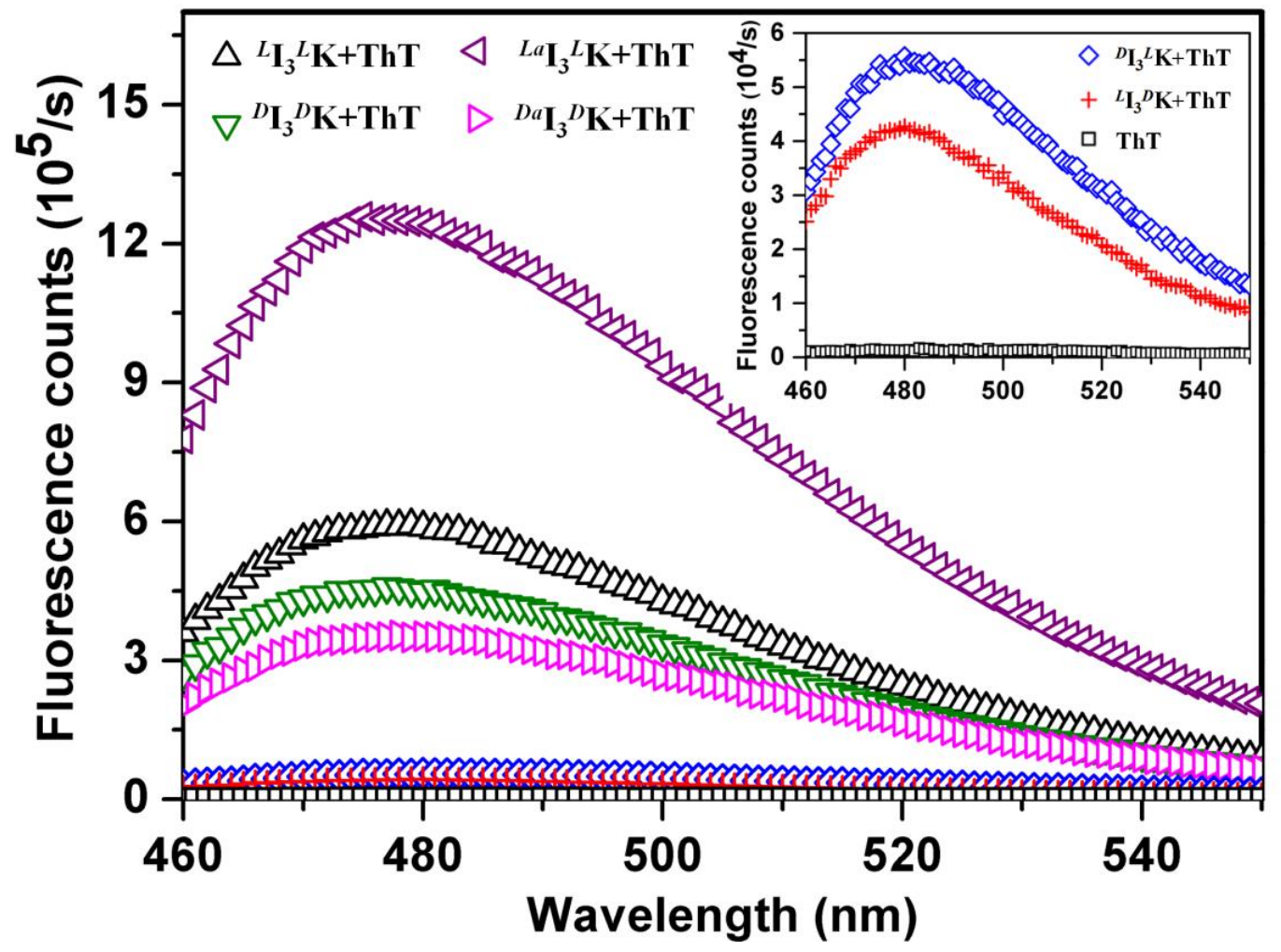

Figure S3. Fluorescence emission spectra (excitation at $442 \mathrm{~nm}$ ) of $50 \mu \mathrm{M}$ ThT in the absence and presence of $8 \mathrm{mM}$ peptides

Fluorescence measurements were performed on a Horiba Jobin Yvon Fluoromax-4 spectrometer at room temperature. ThT was added into the aged peptide solutions $(8 \mathrm{mM}$ and $\mathrm{pH} 7.0$ ) at a final concentration of $50 \mu \mathrm{M}$. Emission spectra were collected from 450 to $550 \mathrm{~nm}$ with an excitation wavelength of $442 \mathrm{~nm}$. The excitation and emission slits were set to $5 \mathrm{~nm}$ and $2.5 \mathrm{~nm}$, respectively. 

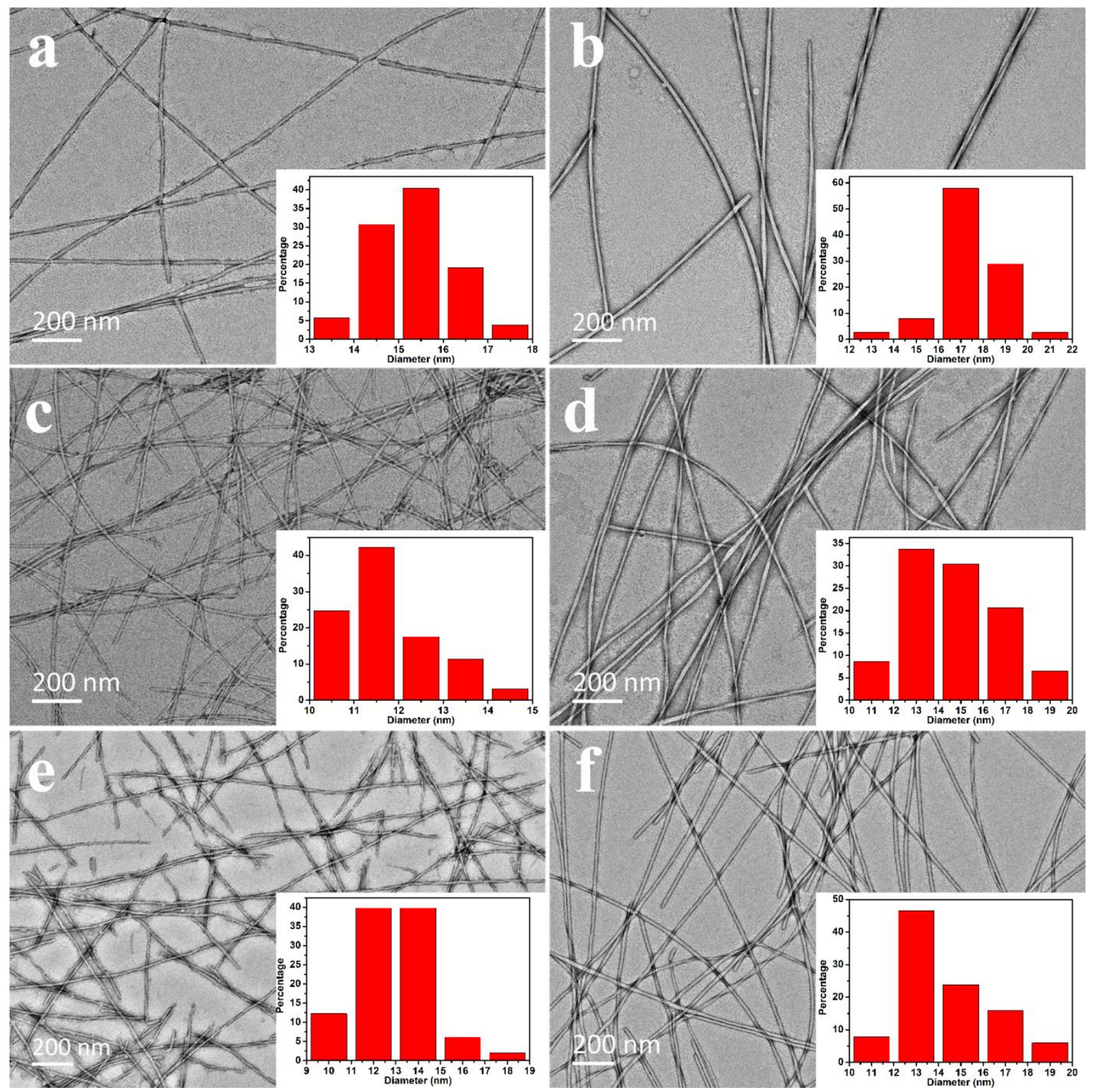

Figure S4. TEM images of (a) ${ }^{L} \mathrm{I}_{3}{ }^{L} \mathrm{~K}$, (b) ${ }^{D} \mathrm{I}_{3}{ }^{D} \mathrm{~K}$, (c) ${ }^{D} \mathrm{I}_{3}{ }^{L} \mathrm{~K}$, (d) ${ }^{L} \mathrm{I}_{3}{ }^{D} \mathrm{~K}$, (e) ${ }^{L a} \mathrm{I}_{3}{ }^{L} \mathrm{~K}$, and (f) ${ }^{D a} \mathrm{I}_{3}{ }^{D} \mathrm{~K}$ at a concentration of $8 \mathrm{mM}$ after incubation in neutral water for 10 days at room temperature. Insets show the diameter distributions of the formed nanofibrils.

All TEM micrographs were taken on a JEOL JEM-2100 UHR electron microscope 
operated at an accelerating voltage of $120 \mathrm{kV}$. For sample preparation, $20 \mu \mathrm{L}$ of the aged peptide solution was dropped onto a copper grid coated with a carbon support film. After adsorption for $\sim 2 \mathrm{~min}$, the excess solution was wiped away using filter paper. Then, the sample was negatively stained with uranyl acetate $(2 \%, w / v)$ aqueous solution for $\sim 4$ min, followed by the removal of the dye solution with filter paper. Finally, the grid was air-dried and viewed on the TEM instrument. 

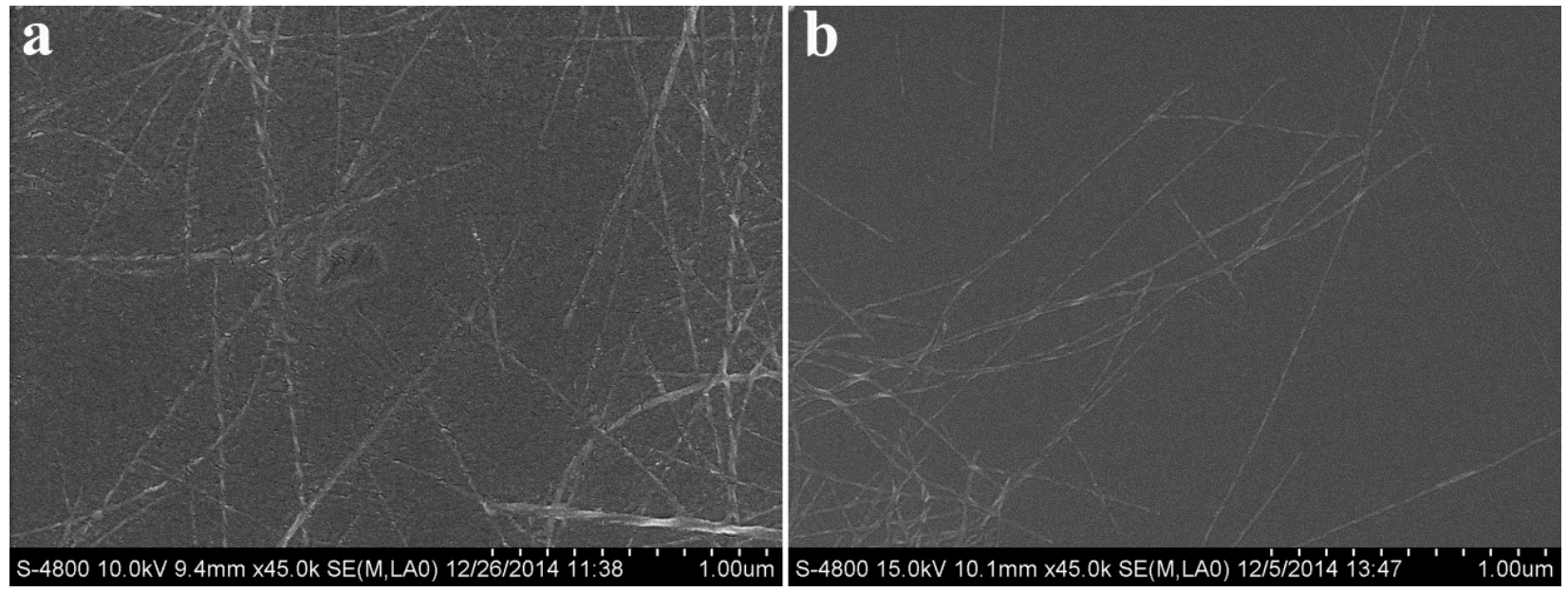

Figure S5. SEM images of (a) ${ }^{D} \mathrm{I}_{3}{ }^{L} \mathrm{~K}$ and (b) ${ }^{L} \mathrm{I}_{3}{ }^{D} \mathrm{~K}$ at concentrations of $8 \mathrm{mM}$ after incubation in neutral water for 10 days at room temperature.

SEM images were recorded on a Hitachi S-4800 (Tokyo, Japan) scanning electron microscope. $10-20 \mu \mathrm{L}$ of the aged peptide solution was placed on a silicon substrate. After the sample was dried under vacuum, a thin layer of platinum was coated for SEM measurements. 

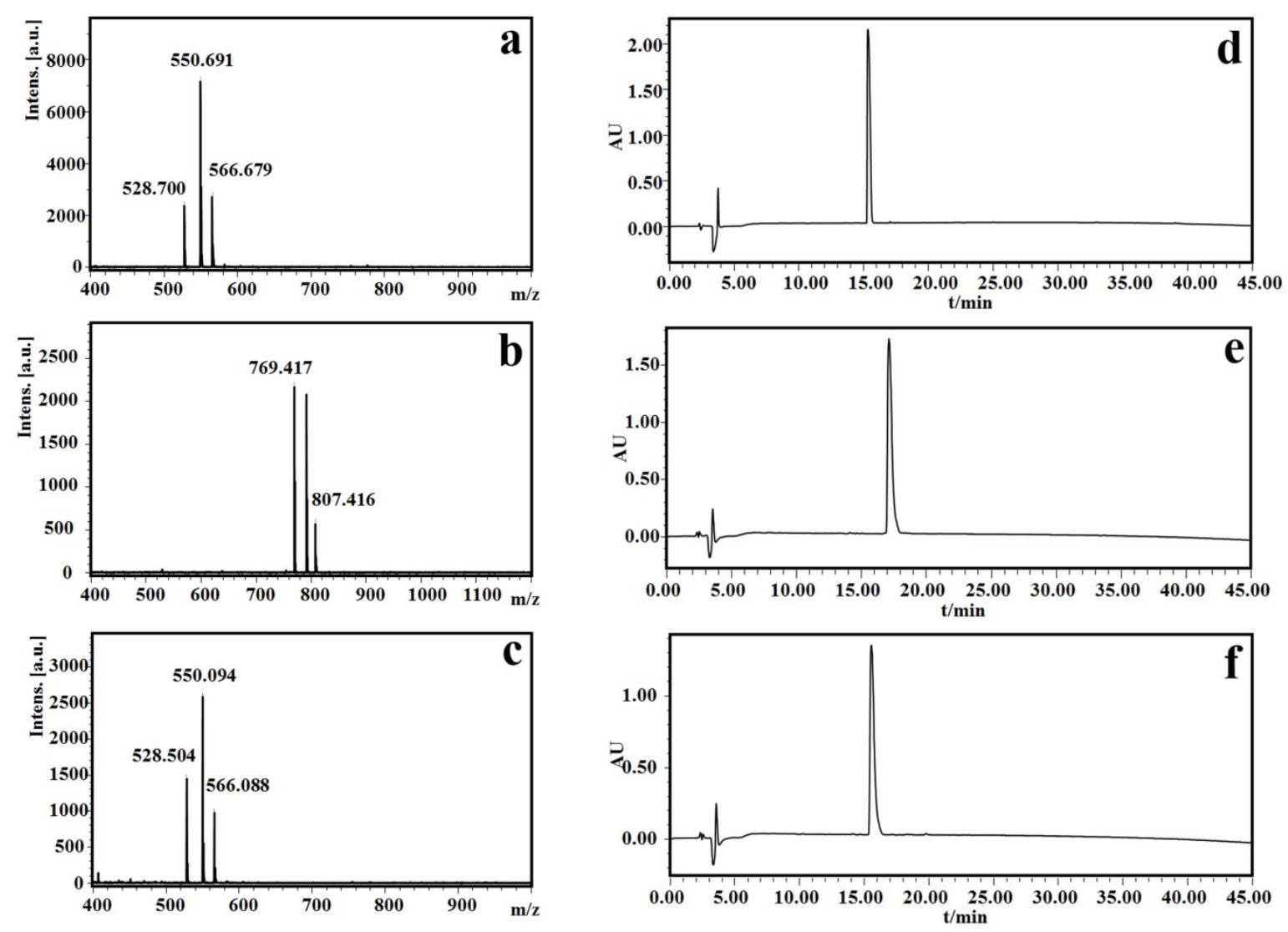

Figure S6. MALDI-TOF mass spectra and RP-HPLC profiles of (a,d) ${ }^{L} \mathrm{I}_{3}{ }^{L} \mathrm{~K}-\mathrm{COOH}$, (b,e) ${ }^{L} \mathrm{I}_{4}{ }^{L} \mathrm{~K}_{2}$, and (c,f) ${ }^{{ }_{1}}{ }_{3} \mathrm{E}$. The experimental conditions for MS and HPLC measurements were the same as those described in Figure S1 and Figure S2. 

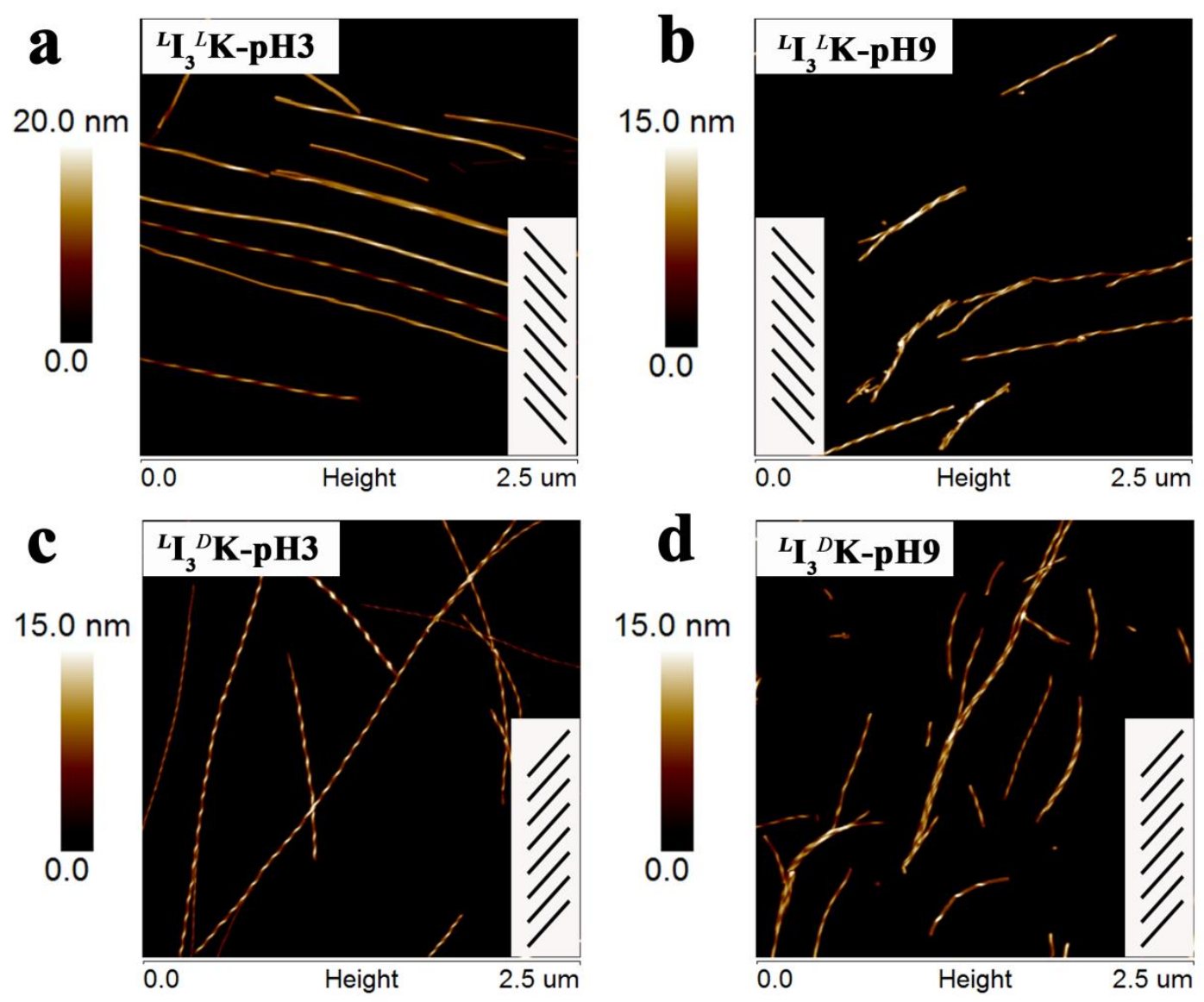

Figure S7. AFM height images of (a,b) ${ }^{L} \mathrm{I}_{3}{ }^{L} \mathrm{~K}$ and (c,d) ${ }^{L} \mathrm{I}_{3}{ }^{D} \mathrm{Kfibrils}$ formed at $\mathrm{pH} 3.0$ and pH 9.0, respectively. The peptide concentration was fixed at $8 \mathrm{mM}$. 


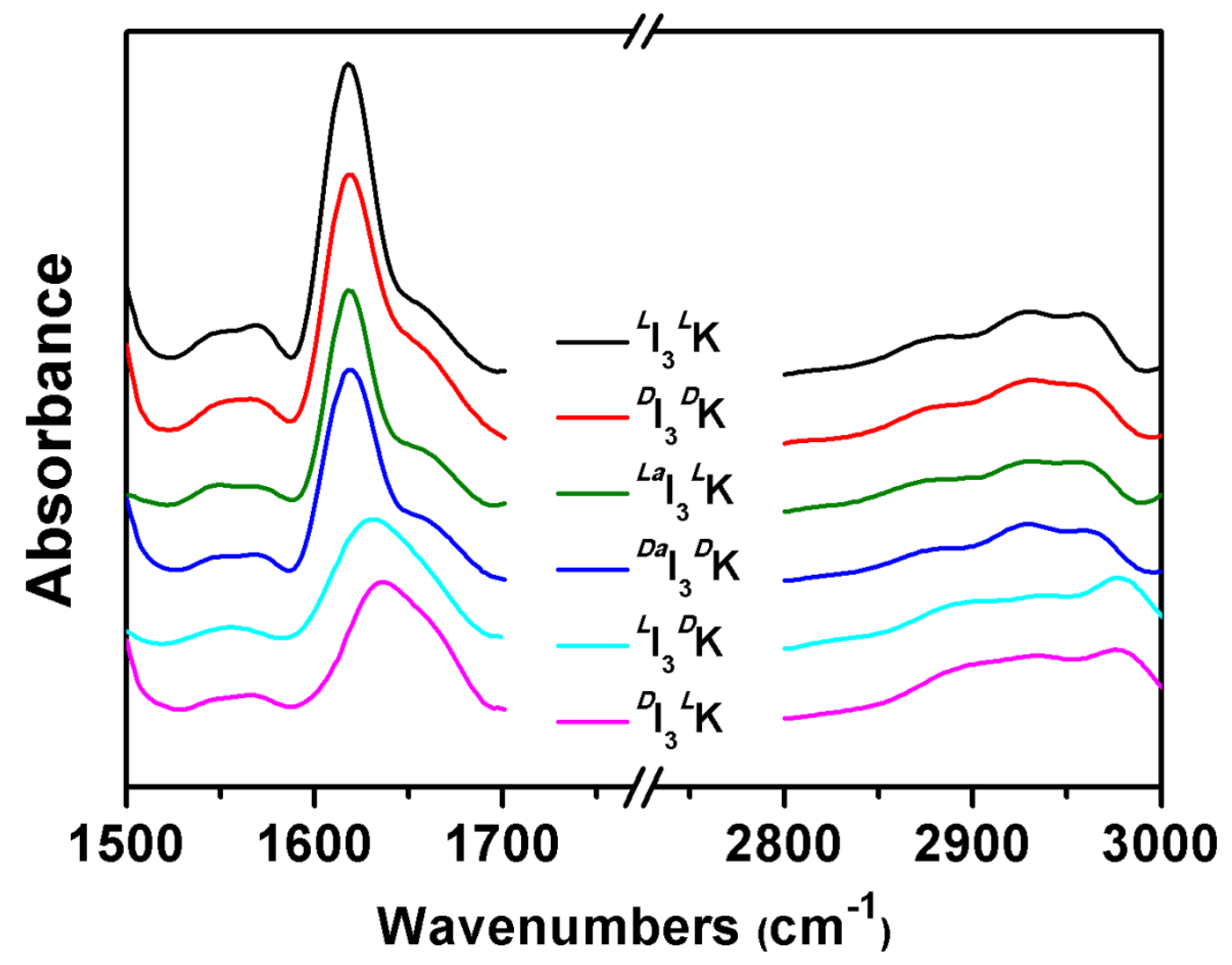

Figure S8. FTIR spectra of ${ }^{L} \mathrm{I}_{3}{ }^{L} \mathrm{~K},{ }^{D} \mathrm{I}_{3}{ }^{D} \mathrm{~K},{ }^{L a} \mathrm{I}_{3}{ }^{L} \mathrm{~K},{ }^{D a} \mathrm{I}_{3}{ }^{D} \mathrm{~K},{ }^{L} \mathrm{I}_{3}{ }^{D} \mathrm{~K}$, and ${ }^{D} \mathrm{I}_{3}{ }^{L} \mathrm{~K}$ at a concentration of $8 \mathrm{mM}$ in neutral water after incubated for 10 days at room temperature.

FTIR spectra were recorded on a Nicolet 6700 FT-IR spectrometer equipped with a DTGS detector using a $0.1 \mathrm{~mm}$ path-length $\mathrm{CaF}_{2}$ cell at room temperature. The number of scans was 256 and the resolution was $4 \mathrm{~cm}^{-1}$ for each sample. All the peptides were dissolved in $\mathrm{D}_{2} \mathrm{O}$ to avoid the interference of $\mathrm{H}_{2} \mathrm{O}$ to the amide I band. After adjusting the solution $\mathrm{pD}$ value to $7.0 \pm 0.1$ with dilute $\mathrm{NaOD}$ in $\mathrm{D}_{2} \mathrm{O}$, the peptide solution was incubated for 10 days at room temperature and without any agitation. 

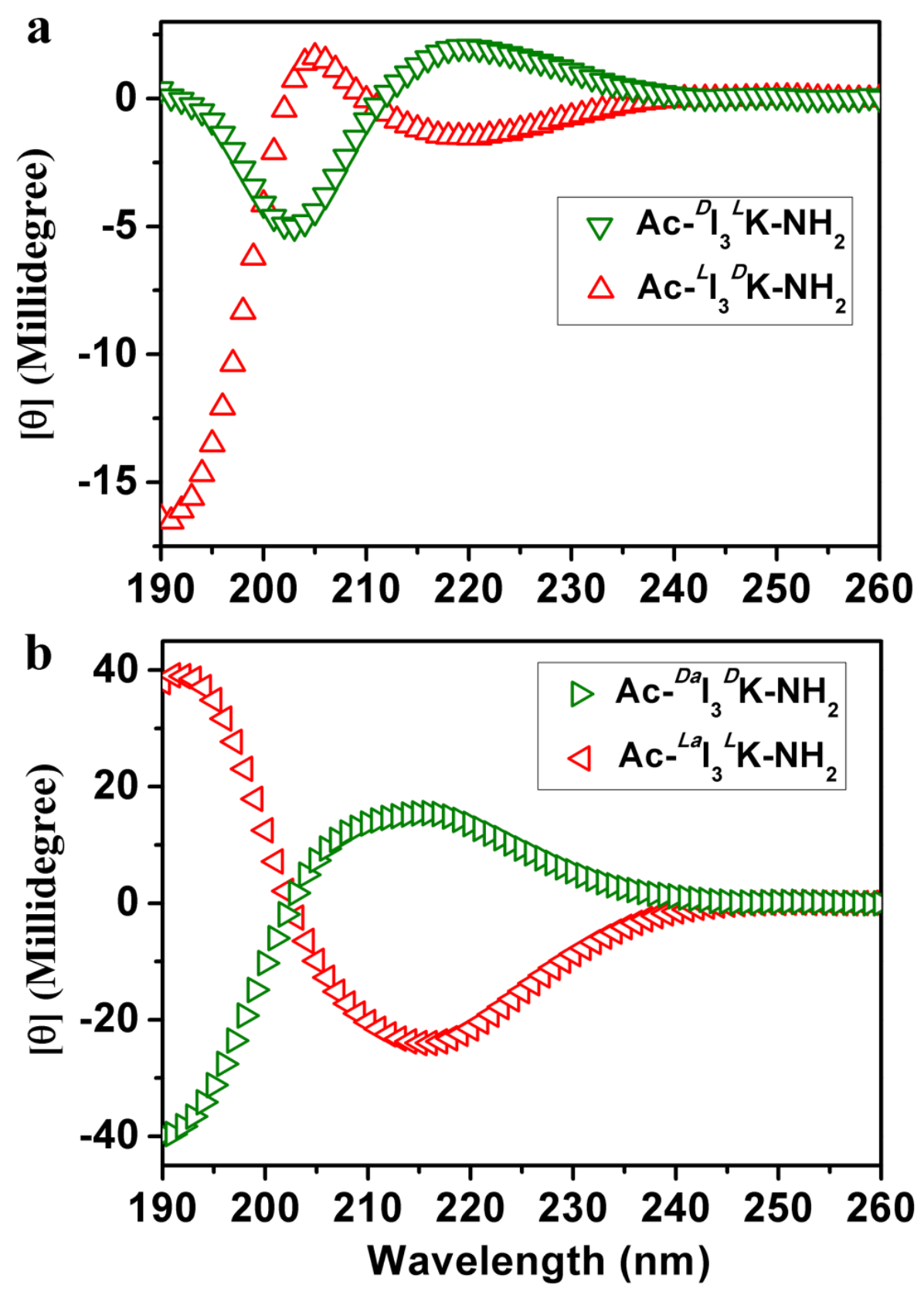

Figure S9. CD spectra of (a) ${ }^{D} \mathrm{I}_{3}{ }^{L} \mathrm{~K}$ and ${ }^{L} \mathrm{I}_{3}{ }^{D} \mathrm{~K}$ and (b) ${ }^{L a} \mathrm{I}_{3}{ }^{L} \mathrm{~K}$ and ${ }^{D a} \mathrm{I}_{3}{ }^{D} \mathrm{~K}$ after dialysis.

The peptide solutions ( $8 \mathrm{mM}$ in neutral water) were dialyzed for 2 days against Milli-Q water using a dialysis bag (cutoff $3500 \mathrm{Da}$ ). Note that because the peptide concentration was changed significantly during dialysis, the presented CD signals were expressed as 
millidegree versus wavelength. 